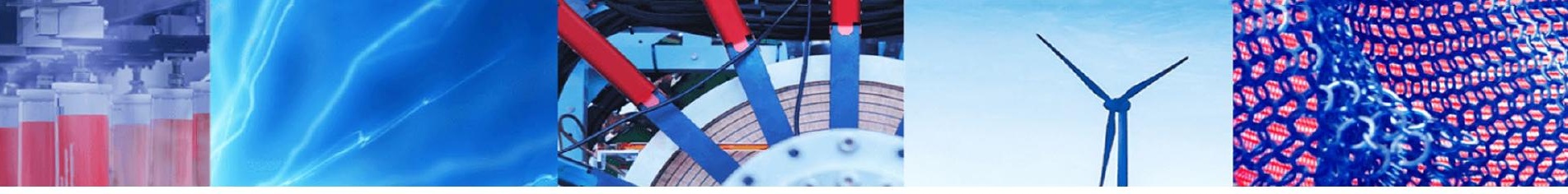

Research Article

\title{
An analysis of droughts in Iran during 1988-2017
}

\author{
Mahdi Ghamghami ${ }^{1} \cdot$ Parviz Irannejad ${ }^{2}$
}

(c) Springer Nature Switzerland AG 2019

\begin{abstract}
Understanding how drought changes have occurred is imperative to enhance the ability of mitigating drought impacts. This consideration encourages carrying out a comprehensive analysis of drought phenomenon in Iran using the standardized precipitation evapotranspiration index (SPEI) on various time scales based on data recorded at 100 weather stations over the period 1988-2017. We employed a nonparametric distribution i.e. the kernel density estimator instead of the commonly-used three-parameter log-logistic distribution for estimating the cumulative distribution functions of the monthly aggregated water deficits/surpluses, and found that the kernel density estimates frequencies of drought classes more accurately than the three-parameter log-logistic. Thereafter, an analysis was conducted by applying a principal component analysis and a Mann-Kendall test to spatio-temporal variables of the nonparametric SPEl at different time scales. Moreover, a bivariate risk assessment was done by calculating the joint exceedance probability using copula functions which depicts joint behavior of the drought characteristics. The spatial variability of drought in Iran revealed the existence of five coherent regions i.e. the northwestern, the southwestern, the southeastern, the northern and the central/eastern over the country. Temporal analysis indicates significant negative trends of surface water balance in all regions by producing a dry condition throughout the country, especially in two last decades (i.e. 1998-2017). However, the northwestern region is dominated by the highest risk of droughts and experienced droughts with longer durations and higher severities. This study was a forward step in considering an aggregative perspective of meteorological, agricultural and hydrological water deficit.
\end{abstract}

Keywords Copula $\cdot$ Kernel density estimator $\cdot$ Risk assessment $\cdot$ Standardized precipitation evapotranspiration index . Water deficit

\begin{tabular}{|c|c|c|c|}
\hline & PCA & Principal component analysis \\
\hline \multicolumn{2}{|c|}{ AET Actual evapotranspiration } & PDF & Probability density function \\
\hline $\mathrm{CDF}$ & Cumulative distribution function & PDSI & Palmer drought severity index \\
\hline CE & Central/eastern & PET & Potential evapotranspiration \\
\hline IPCC & International panel for climate change & PST & Positive significant trend \\
\hline JCDF & Joint CDF & $\mathrm{RP}$ & Return period \\
\hline JEP & Joint exceedance probability & SE & Southeastern \\
\hline KDE & Kernel density estimator & SEDI & Standardized evapotranspiration deficit index \\
\hline $\mathrm{K}-\mathrm{S}$ & Kolmogorov-Smirnov test & SPEI & Standardized precipitation evapotranspiration \\
\hline MK & Mann-Kendall test & & index \\
\hline $\mathrm{N}$ & Northern & SPI & Standardized precipitation index \\
\hline NST & Negative significant trend & SW & Southwestern \\
\hline NW & Northwestern & & \\
\hline
\end{tabular}

Mahdi Ghamghami, mghamghami@ut.ac.ir; Parviz Irannejad, piran@ut.ac.ir | 'Department of Irrigation and Reclamation Engineering, University of Tehran, Karaj, Iran. ${ }^{2}$ Geophysics Institute, University of Tehran, Tehran, Iran.

SN Applied Sciences (2019) 1:1217| https://doi.org/10.1007/s42452-019-1258-x

Received: 12 May 2019 / Accepted: 10 September 2019 / Published online: 13 September 2019 


\section{Introduction}

Drought, briefly described as limited access to water, is a recurring natural hazard that can cause devastating agricultural impacts $[23,71,77,80]$. In the two last decades, Iran has been most seriously affected by this damaging disaster. Moreover, a gravely climbing trend of water demand in the country due to social issues such as population growth, and global warming exacerbated drought impacts whereupon the water shortage has taken evidently place. Therefore, it is indispensable to analyze spatio-temporal drought characteristics, particularly when drought lasts for months or even years. Spatiotemporal drought analysis is imperative to enhance our ability for drought monitoring, to understand changes in drought vulnerabilities and to mitigate drought impacts $[25,82]$.

In general, the first step in drought characterization and monitoring is the development of reliable quantitative measures, such as drought indices [74]. The idea behind the development of drought indices is to objectively identify drought characteristics, such as duration and severity as well as its spatio-temporal pattern [28, $61,74]$. Drought indices reflect drought impacts that are being experienced $[14,25]$. In fact, indices give us a better understanding of the drought changes occurred in the past [77] for more efficacious management of the future drought risk. Hence, drought event identification would be the basis of drought risk assessment [80].

For studying meteorological, agricultural and hydrological droughts, precipitation is the major parameter in structure of an index $[37,39,72]$. For example, the standardized precipitation index (SPI) presented by McKee et al. [41] relies only on precipitation data. In two recent decades, the SPI has received attention by researchers (e.g. [20,42,43,45] due to its compatibility for the analysis on various time scales. However, the SPI does not consider the impact of other variables, such as temperature, on droughts $[25,68]$. According to the International Panel for Climate Change (IPCC) reports, the global temperature has had an obvious increasing trend in recent decades [26]. This could have affected the variability of drought episodes $[23,25,50,71,79]$. Other indices, such as Palmer drought severity index (PDSI, [46], also have several shortcomings such as limitation of application in wet regions [79] and problem in spatial comparability $[25,67]$.

Vicente-Serrano et al. [67] introduced a temperaturebased drought index, namely standardized precipitation evapotranspiration index (SPEI), to tackle the drawbacks of above indices. The SPEI combines the advantages of both PDSI and SPI, so that it has a simple calculation procedure while maintaining the multi-temporal flexibility of the SPI along with sensitivity to evapotranspiration demand similar to PDSI [23]. Various researchers (e.g. $[7,23,25,33,39,60,77,79]$ applied SPEl in drought analysis, because it can consider the impacts of global warming on drought occurrences [9, 35, 36, 59, 81]. For instance, Mathbout et al. [39] demonstrated that the SPEI is superior to SPI due to its capability in identifying the role of evapotranspiration and temperature variability in drought characteristics, and consequently its ability in detecting drier conditions. In a new study, VicenteSerrano et al. [70] compared two indices i.e. the SPEI and the standardized evapotranspiration deficit index (SEDI) proposed by Kim and Rhee [31] in identifying drought severity globally. They showed that though the SPEI does not require estimation of the actual evapotranspiration (AET), it has a similar performance to the SEDI that use the AET. Over Iran, Bazrafshan [5] suggested the SPEI rather than SPI for more effective monitoring of droughts due to the determinative role of temperature in mostly dry regions like Iran. Accordingly, the SPEI has been recognized as a better monitoring approach for drought and flood analysis.

The SPEI was established based on monthly climatic water balance represented by the difference $(\Delta)$ between monthly precipitation and potential evapotranspiration (PET) rather than only precipitation. The primary formulation of the SPEI represented by Vicente-Serrano et al. [67] employs the Thornthwaite equation [62] for PET calculation since it relies only on temperature and latitudinal data. Tan et al. [60] and Yang et al. [79] also used Thornthwaite for estimating PET. However, Jensen et al. [27] and Van der Schrier et al. [64] found that Thornthwaite underestimates PET in arid and semiarid regions and overestimates it in humid regions, respectively. Also, $\mathrm{Xu}$ et al. [77] concluded that applying Thornthwaite for estimating PET exaggerated the drying trend during 1961-2012 in the mainland China and Chen et al. [6] and Lang et al. [32] showed that Thornthwaite would give unreliable results under dry conditions. To overcome this problem, various researchers $[7,77]$ employed other methods, such as Penman-Monteith (PM), for estimating PET. Moreover, Li et al. [34] used pan evaporation as the SPEI input and indicated that SPEI calculated by pan evaporation has a better agreement with the SPEI calculated by PM than Thornthwaite. Furthermore, Homdee et al. [23] used AET instead of PET for the SPEI calculation and developed the standardized precipitation actual evapotranspiration index (SPAEI). They confirmed that using SPAEI instead of SPEI provides substantially different drought severity results. However, data availability determines what information can be served for introducing a drought index. 
The SPEI is calculated based on the probability of atmospheric evapotranspiration demand on different time scales. Thus, fitting an appropriate probability distribution to SPEI values of a certain time scale is the first step for calculating this index. According to literature, it was found that the three-parameter log-logistic distribution fits suitably to the monthly aggregated $\Delta$ values [67]. Therefore, similar to the SPI, the SPEI theory was first introduced on the basis of a parametric probability density function (PDF). However, parametric methods have some limitations in constructing drought indices; an empirical probability can be used as a more reliable alternative for calculating an index using a distribution-free function [24].

Calculation of parametric distributions is based on parameters that determine the properties of the probability curve such as shape, skewness and kurtosis. This can lead to misleading results, especially at local scales such as distribution tails. On the other hand, a nonparametric approach (e.g. kernel density estimator, KDE) estimates the PDF of observations, not only by taking into account various parameters, but by using all observations. This can affect frequencies of the SPEI classes, since it is expected that these frequencies should follow the standard normal distribution. Sienz et al. [53] compared several parametric methods in terms of frequencies of drought classes using the SPI and indicated that some distributions may overestimate or underestimate the frequencies.

In recent studies, nonparametric approaches in modeling drought indices have been frequently used by many researchers $[13,19,24,58,85]$. Nevertheless, evaluation of calculated frequencies of drought events using nonparametric continuous PDF compared to those based on commonly-used parametric approach i.e. log-logistic has not been performed. This has motivated the current study which aims at (1) calculating a nonparametric SPEI using data recorded at 100 synoptic stations over Iran during the period 1988-2017, (2) comparing the performance of nonparametric and parametric methods in deriving the expected frequencies, (3) evaluating the trends significance, (4) identifying homogeneous regions in terms of drought spatial variabilities, and (5) assessing regional drought risk. This paper contributes to current knowledge of drought by carrying out a comprehensive spatiotemporal analysis of recent droughts in Iran using a nonparametric SPEI.

\section{Data and study area}

Iran is situated in West Asia with climate diversity from arid to very humid. Most of the arid and semiarid lands are located in the central to eastern and humid lands are located in the northern and western parts of Iran. Monthly precipitation and temperature data from 100 synoptic stations for the 31-year period of 1987-2017 were obtained from the Iranian Meteorological Organization. These stations were selected based on the completeness of dataset and length of climatic record. The geographical locations of the stations are shown in Fig. 1. Figure 1 also shows the geographical distribution of the aridity index [63] over Iran. This index varies from 0 (very arid) to 2.2 (very humid).

\section{Methodology}

\subsection{The nonparametric SPEI}

The SPEI was developed by Vicente-Serrano et al. [67] for drought monitoring. This index accommodates the combined influence of precipitation and temperature, and is suitable for identifying drought episodes, evaluating drought characteristics i.e. duration and severity, and defining the spatial pattern of drought using climatic water balance anomalies.

The SPEI calculation procedure is similar to that of the SPI [41], but it uses the difference $(\Delta)$ between monthly precipitation and potential evapotranspiration rather than only precipitation used in the SPI. Values of $\Delta$ are then aggregated at different time scales to calculate drought severity for various types of meteorological (short-term scale) and hydrological/agricultural (long-term scale) droughts $[4,30,56]$. In this study, the SPEI was calculated for 1-, 3-, 6-, 9- and 12-month time scales (hereafter SPEI1, SPEI3, SPEI6, SPEI9 and SPEI12, respectively). Due to insufficient data during the study period, we applied the

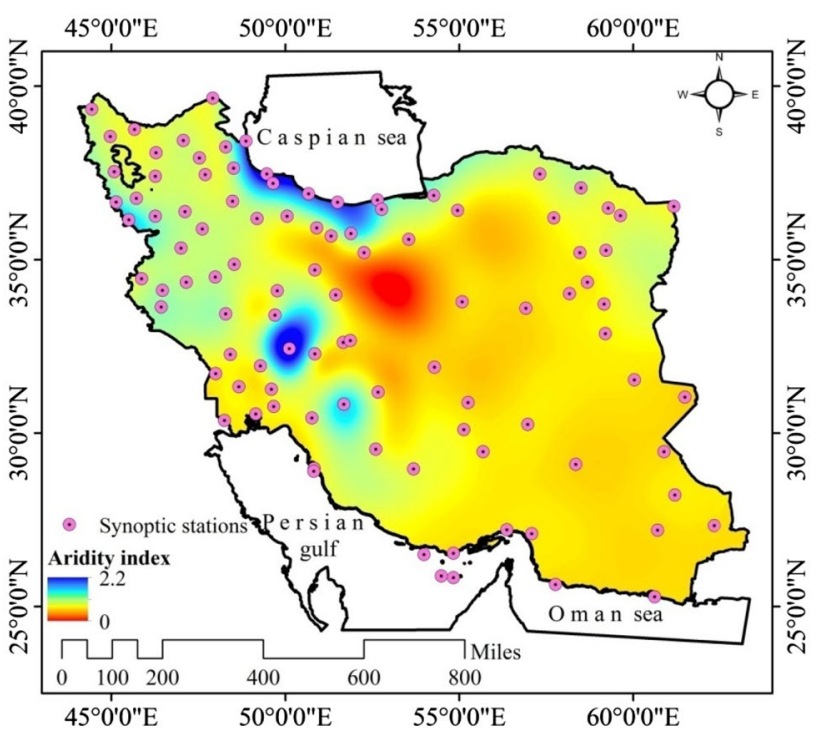

Fig. 1 Location of synoptic stations and general aridity status in Iran 
modified Thornthwaite parameterization [76] as a simple approach for estimating PET. The modified Thornthwaite reduces over- and under-estimation of PET as calculated by the Thornthwaite method [78]. Details of the formulation of the modified Thornthwaite method can be found in Willmott et al. [76] and Yao et al. [78]. Thornthwaite approach requires only monthly mean temperature and station's latitude [62] and, therefore, is easy to apply [25, 28].

Three-parameter log-logistic distribution was suggested by Vicente-Serrano et al. [67] to fit the twelve aggregated $\Delta$ time series (January to December). The scale, shape, and location parameters determining the loglogistic distribution are obtained using the maximum likelihood method. Similar to the SPI, the SPEI is calculated by transforming the cumulative distribution function (CDF) to the standard normal CDF.

Since the SPEI is a normalized variate, it is expected that probabilities of different wet and dry classes follow the normal distribution. The expected probabilities for each class of SPEI are represented in Table 1. The deviation of the aggregated $\Delta C D F$ from the standard normal CDF leads to overestimation or underestimation of the frequencies of estimated classes with respect to the expected ones [53]. This is highly dependent on the goodness of fit of the CDF to the data.

In this study, we employ the KDE developed by Sharma et al. [49] instead of the three-parameter log-logistic for estimating the CDFs of the monthly aggregated water deficits or surpluses. The KDE method estimates the PDF without any assumption about the probability distribution of the data. In this method, all observed values contribute to the estimation of the PDF of a given observation $(x=\Delta)$ with the contribution of each observation determined by a kernel density function. The effective parameter in this function is the bandwidth [49]. Different forms of kernel functions have been used in different studies among which the most popular one is the standard normal function. It has been analytically proven that the form of the

Table 1 The SPEI classes and their expected probabilities based on standard normal distribution

\begin{tabular}{llll}
\hline SPEl class & Class symbol & Description & $\begin{array}{l}\text { Expected } \\
\text { probability } \\
\text { (\%) }\end{array}$ \\
\hline Larger than 2.0 & ew & Extreme wet & 2.3 \\
$1.5-2.0$ & sw & Severe wet & 4.4 \\
$1.0-1.5$ & $\mathrm{mw}$ & Moderate wet & 9.2 \\
-1.0 to 1.0 & $\mathrm{n}$ & Normal & 68.2 \\
-1.5 to -1.0 & $\mathrm{md}$ & Moderate drought & 9.2 \\
-2.0 to -1.5 & sd & Severe drought & 4.4 \\
Less than -2.0 & ed & Extreme drought & 2.3 \\
\hline
\end{tabular}

kernel function has no major role in the performance of the method $[10,47]$. The estimated frequency for a specific $x$ value is found from the standard normal function:

$\hat{f}(x)=\frac{1}{n h} \sum_{i=1}^{n} \frac{1}{(2 \pi)^{1 / 2}} \exp \left[-\frac{\left(x-x_{i}\right)^{2}}{2 h^{2}}\right]$

where $n$ and $h$ are number of observations and the global bandwidth, respectively. The value for the exponential component of this equation is between 0 and 1 , and determines the contribution of independent data in estimating the value of the PDF for each $x$. Observations closer to the $x$ observation have a higher contribution in estimating the value of the PDF. Hence, to estimate the density of any observation, a standard normal kernel function, centered on the given observation, is fitted to the data. In other words, the $n$ normal kernel functions are fitted to the $n$ independent observations to determine the probability density function.

Determination of a suitable value for $h$ is imperative. The large values of the bandwidth cause an excessively even estimation and its small values result in an uneven estimation. To achieve a better estimate of the PDF curve, the local bandwidth $\left(h_{i}\right)$ should be used [49]. In this case, a separate $h$ parameter is defined for each observation. Abramson [2] presented a formulation for the local bandwidth as:

$h_{i}=h\left[\hat{f}\left(x_{i}\right) / g\right]^{-1 / 2}$

where $\hat{f}\left(x_{i}\right)$ is the probability density function based on the global bandwidth and $g$ is the geometric mean of $\hat{f}\left(x_{i}\right)$. Silverman [54] introduced an analytical equation to estimate the global bandwidth as:

$h=1.06 \sigma n^{-1 / 5}$

where $\sigma$ is the standard deviation of data. According to Eq. (1), the optimized local bandwidth is the only required parameter for the aforementioned nonparametric method. The CDF is the integral of the PDF (Eq. 4):

$F(x)=\frac{1}{n h \sqrt{2 \pi}}\left(\int_{-\infty}^{x} e^{-\frac{\left(x-x_{1}\right)^{2}}{2 h^{2}}}+\int_{-\infty}^{x} e^{-\frac{\left(x-x_{2}\right)^{2}}{2 h^{2}}}+\cdots+\int_{-\infty}^{x} e^{-\frac{\left(x-x_{n}\right)^{2}}{2 h^{2}}}\right)$

There is no analytical solution for Eq. (4) and hence it is calculated numerically.

\subsection{Drought event characterization}

In the present study, the SPEI values on five time scales were calculated as they are capable of representing the meteorological (SPEI1), agricultural (SPEI3 and SPEI6) and hydrological (SPEI9 and SPEI12) droughts [60]. A drought 
event or episode is defined as a period in which the SPEI is continuously negative and less than -1.0. Accordingly, duration, severity and spatial variability of droughts can be identified $[21,39,73]$.

We apply the Mann-Kendall (MK) test $[29,38]$ to the SPEl time series to detect if a trend in monthly SPEI time series is statistically significant at $99.99 \%, 99 \%, 95 \%$ and 90\% confidence levels over the period 1988-2017. The MK test is a well-known non-linear method based on the ranking to time sequences of the observations [18]. Details for computing the standard normal test statistic (Z) can be found in Yang et al. [80] and Hui-Mean et al. [25]. At the above confidence levels, the null hypothesis of no trend is rejected if $|Z|>3.29,|Z|>2.58,|Z|>1.96$ and $|Z|>1.64$, respectively.

\subsection{Spatial patterns identification}

In dealing with climatic and hydrological data, widespread statistical multivariate analyses, such as the principle component analysis (PCA), have considerable applications [57]. We carried out PCA to define the spatial variability of drought. The PCA was applied to 100 time series of the SPEI separately for each accumulated period in order to recognize the most influencing parameters responsible for drought patterns delineation. This can subsequently be used in regional risk assessment. In climate studies, PCA is mostly applied to reduce the number of variables and produce factors that will explain most of the variance or analyze spatial and temporal variability of various phenomena such as drought (see $[16,39,40,48,65,66,86]$.

We extracted principle factors by applying two types of rotations i.e. varimax orthogonal and promax PCA with Kaiser Normalization [22] on 100 time series (synoptic stations) of the SPEl for all time scales, separately. In case of varimax orthogonal rotation, similar to that reported by Mathbout et al. [39], we could not find coherent and unoverlapped spatial patterns for factor loadings. Besides, in some cases factor loadings were negative and therefore factor scores had a trend unlike the original SPEI values. Accordingly, we analyzed only outputs of promax PCA in a spatial mode i.e. S-mode. Mathbout et al. [39] and Martins et al. [40] showed that S-mode provides areas with close temporal behavior. The PCA produces a temporal sequence of the scores for each $P C$ by multiplying original SPEl by factors coefficients. Each PC is associated with a spatial structure derived from loadings, so that regions with values of factor loadings greater than 0.4 can be considered almost exclusive areas $[39,75]$. In the present study, the decision on the number of components to retain was made using North's rule of thumb [44]. We also carried out a trend analysis using the MK test on temporal sequences of PC scores.

\subsection{Bivariate risk assessment}

By extracting spatio-temporal patterns of drought variability, we did a bivariate risk assessment in order to explore the correlations between drought characteristics. At first, it is necessary to assign two drought characteristics i.e. duration (D) and severity (S) to each event according to Subsection 3.2. Duration is the number of consecutive months of the drought event (the months when SPEI values are smaller than - 1.0). Severity is the cumulative values of SPEI within the drought duration. For convenience, severity of drought event is taken to be positive [15].

The relationship between characteristics of drought events is represented by a bivariate joint CDF (JCDF). This bivariate JCDF can be expressed in terms of copula function [55], since drought severity and duration may not have identical distribution functions. The copula theory was introduced to model stochastic nature of multivariate processes in which a multivariate distribution function is constructed using several univariate distribution functions $[11,15,52,83,84]$. It can depict the dependence structure between variables, independently of the marginal behavior of the involved variables $[17,35,36]$. We compared five common copula functions i.e. Clayton, Normal, Gumbel-Hougaard, T and Frank which have wide applications to analyze the JCDF and calculated bivariate return periods of drought events. To select the suitable bivariate model, we applied the Akaike information criterion (AIC). The methodology for calculating the AIC values is described in Ganguli and Reddy [15]. The bivariate return period is used to estimate the recurrence interval of drought events with the severity and the duration greater than or equal to a given value. The bivariate return period $(R P)$ can be defined as $[35,36,51]$ :

$R P=\frac{E(L)}{P(D \geq d, S \geq s)}$

where $E(L)$ is inter-arrival time of drought, defined as the time interval between beginnings of two consecutive drought events, and $P(D \geq d, S \geq s)$ is the joint exceedance probability (JEP), or risk, depicting joint behavior of the characteristics. The JEP is calculated as:

$P(D \geq d, s \geq s)=1-F_{D}(d)-F_{S}(s)+F_{D S}(d, s)$

where $F_{D}(d)$ and $F_{S}(s)$ are the marginal CDFs of duration and severity, respectively, and $F_{D S}(d, s)$ is bivariate JCDF expressed in terms of the selected copula function. Thus $F_{D}(d), F_{S}(s)$ and $F_{D S}(d, s)$ should be derived prior to finding the bivariate return period. It is expected that various combinations of duration and severity produce different return periods. 


\section{Results and discussion}

\subsection{KDE performance}

The performances of two PDFs, i.e. log-logistic and KDE were compared in terms of the frequencies of SPEI classes. As previously stated, any deviation from the probabilities mentioned in Table 1 results in underestimation or overestimation of the frequency of a drought class, which is important in drought risk assessment. This discrepancy affects the computed drought return periods. Differences between the calculated frequencies using the two PDFs and those expected for SPEls of
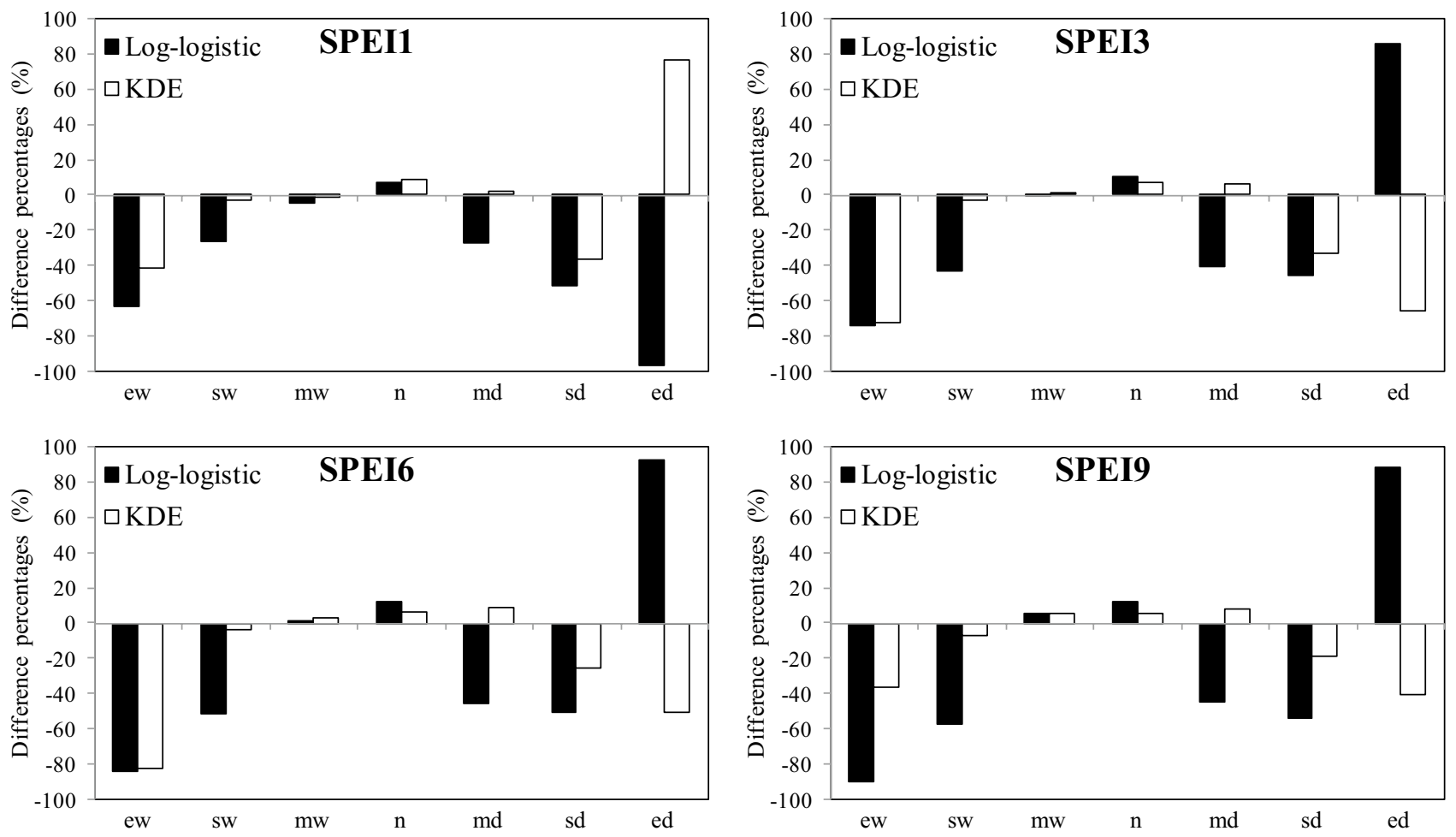

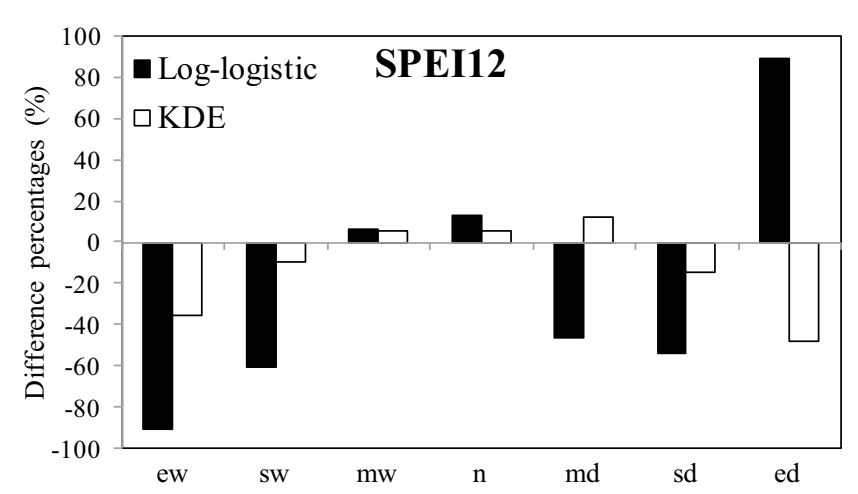

Fig. 2 Average difference percentages of various time scales SPEI classes based on KDE and log-logistic distributions obtained from 100 stations throughout the country. The class symbols ( $x$-axis) were introduced in Table 1 
the differences are smaller than $60 \%$ for KDE and greater than $80 \%$ for the log-logistic distribution. This condition also holds for severe and moderate droughts with difference percentages less than extreme ones. Overall, the $\mathrm{KDE}$ performs better than the log-logistic in estimating the frequency of drought classes on various time scales. The mean absolute difference of drought classes is more than $60 \%$ for the log-logistic, but less than $30 \%$ for KDE.

Despite the flexibility of the log-logistic to fit to various data and its suitability for negative values [67], the quite bad fitting of the distribution tails and middle to data results in considerable deviations in frequencies of drought classes. This may negatively impact the accuracy of the estimation of drought characteristics, such as return periods of drought classes. Since the return period plays a key role in studies of hydrology and water resources management, reduction of estimation error of drought frequencies is necessary for efficient management and making right decisions under drought conditions [53].

Using KDE in the SPEl structure has two advantages: (1) The KDE has only one parameter that is easy to calculate mathematically and does not require the inclusion of other parameters to assess skewness and kurtosis of data; and (2) The KDE presents more efficient results than the loglogistic distribution as found by comparison of percentage differences for each class of SPEI. However, the limited length of the present study period makes it impossible to accurately estimate the frequency of drought spells.

\subsection{Local trend analysis}

Using monthly precipitation and PET calculated by modified Thornthwaite approach, the SPEI time series for 100 stations were derived based on the KDE distribution. Trends' significance based on MK test for all stations and time scales are shown in Fig. 3. Negative significant trends (NST) are found in many stations and the number of stations with NST in all confidence levels increases as time scale becomes longer. Besides, the number of stations with non-significant trend (NS) or positive significant trend (PST) decreases by increasing the time scale. For example, at the $99.99 \%$ confidence level, NST was detected at 27 , $37,48,59$ and 66 stations for SPEI1, SPEI3, SPEI6, SPEI9 and SPEI12, respectively. At respectively, 44, 38, 29, 21 and 19 stations there were either NS or PST (at $90 \%$ confidence level).The results indicate that as the accumulation period for calculation of the SPEl increases from 1 to 12 months, drought becomes more widespread.

The box-whisker plots of $Z_{M K}$ scores depicting trends in monthly standardized precipitation, temperature and SPEls of 100 synoptic stations on various time scales are plotted in Fig. 4. According to the figure, significant positive trend of drought can be categorized into three situations: (1) increasing trend of PET and no or increasing trend of precipitation, but the trend is more significant for PET; (2) decreasing trend of precipitation and no or decreasing trend of $\mathrm{PET}$, but the trend is more significant for precipitation; and (3) increasing trend of PET and decreasing trend of precipitation which lead to a more sever water deficit and more persistent drought. The PET is strongly dependent on temperature; therefore, the higher values of temperature indicate the increasing crop water demand.

As showed in Fig. 4, there is a seasonal variability in precipitation and temperature trends which, in turn, produces various conditions in terms of drought severity in different months. In general, most of the stations experiencing drought in winter (January-March) have a significant increase in temperature and consequently in the $\mathrm{PET}$, and a significant decrease in precipitation. However, a more significant increasing trend of temperature compared to rainfall can be seen from April to September that has led to water deficit in the spring and summer seasons. In August and September, many stations experience an upward trend in precipitation time series. In summer (July-September), the number of stations that experience a significant increasing trend in temperature is less than that in spring (April-June) and consequently, the SPEI1 trend is significant in fewer stations. Nevertheless, trends in longer SPEls in the summer are similar to those in the spring.

Conditions in October are similar to those in summer, i.e. there is greater contribution of temperature than precipitation in producing droughts. However, November, with an upward trend in precipitation and a downward trend in temperature for much of the country, has conditions unlike other months. It causes the SPEI1 of November to have an increasing trend in the overwhelming majority of the stations. Droughts occurred in December are influenced by a downward trend in precipitation while there has been no trend or decreasing trend in temperature. Although January SPEI1 values are relatively large negative, its SPEI3 shows wetter conditions because of wet condition in November and December.

Analysis shows that drought changes in winter are due to the third situation, those in spring and summer as well as October are due to the first situation and those in December are caused by the second situation. Besides, 1-month water deficit has not occurred in November over the country. Therefore, throughout Iran has experienced strong water deficit in winter season during the two recent decades. This has led to more severe drought episodes and hence required an effective drought management to mitigate the impacts. In general, stations where a significant negative trend of the SPEI at high confidence levels was detected are irregularly spread throughout the country. 

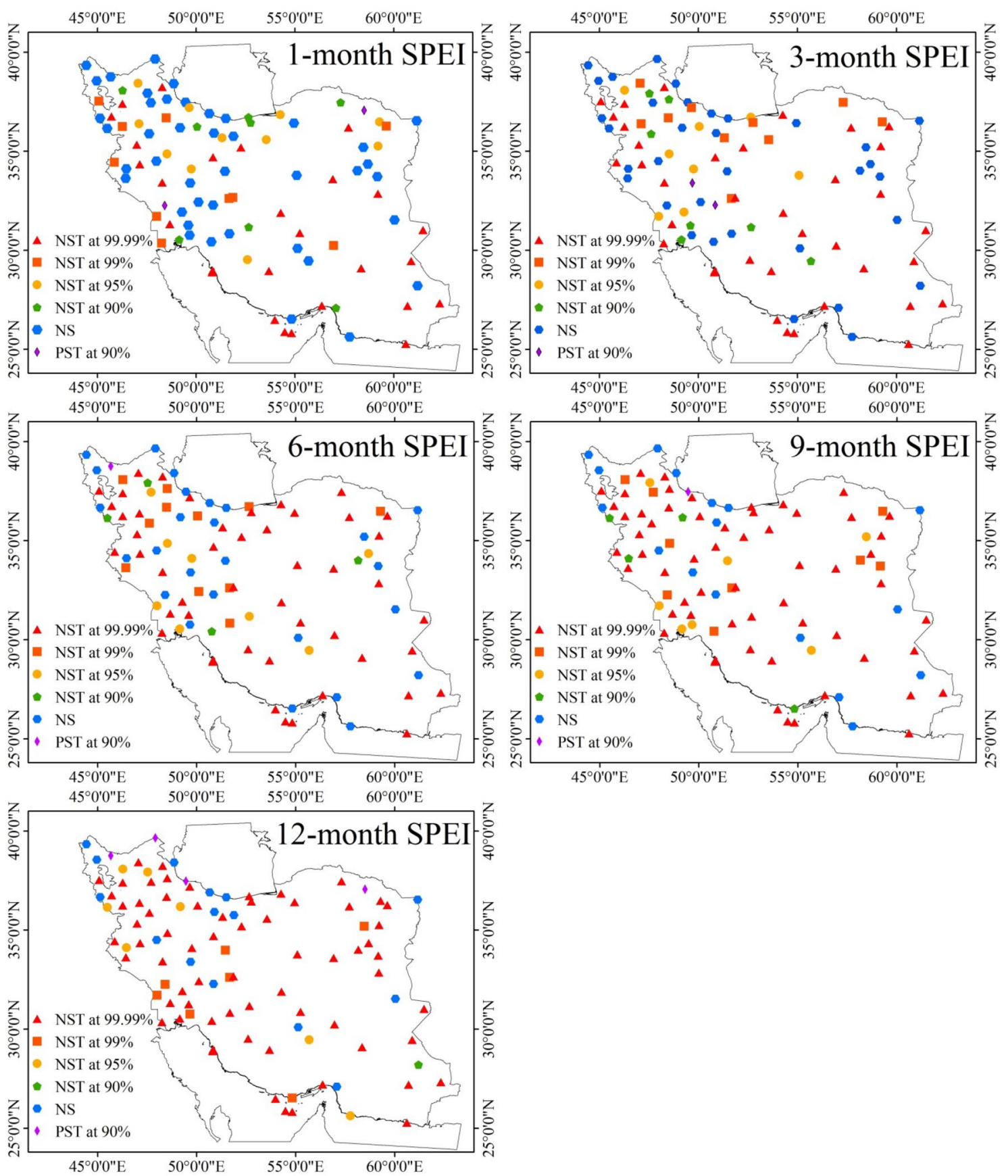

Fig. 3 Significance of trends based on the MK test throughout 100 synoptic stations

\subsection{Spatio-temporal analysis}

According to North's rule of thumb [44] and control of the scree plots of the Eigen-values associated with all time scales, the number of PCs among 100 spatial variables should be selected as those explaining at least $55 \%$ of the total variance. In all cases, the total explained variances of the five retained PCs are higher than $55 \%$; the highest value was obtained for the SPEI12 (69\%) and the lowest for SPEI1 (58.6\%). Hence, five leading rotated promax PCS were retained meaning that the first five PCs should represent the spatial distribution of drought well throughout the country. This suggests that the country is composed of five distinct regions characterized by different drought variabilities. The first rotated principle component (PC1) accounts for $32 \%, 35.7 \%, 39.9 \%, 41 \%$ and $42 \%$ of the total variance for SPEI1, SPEI3, SPEI6, SPEI9 and SPEI12, respectively. 

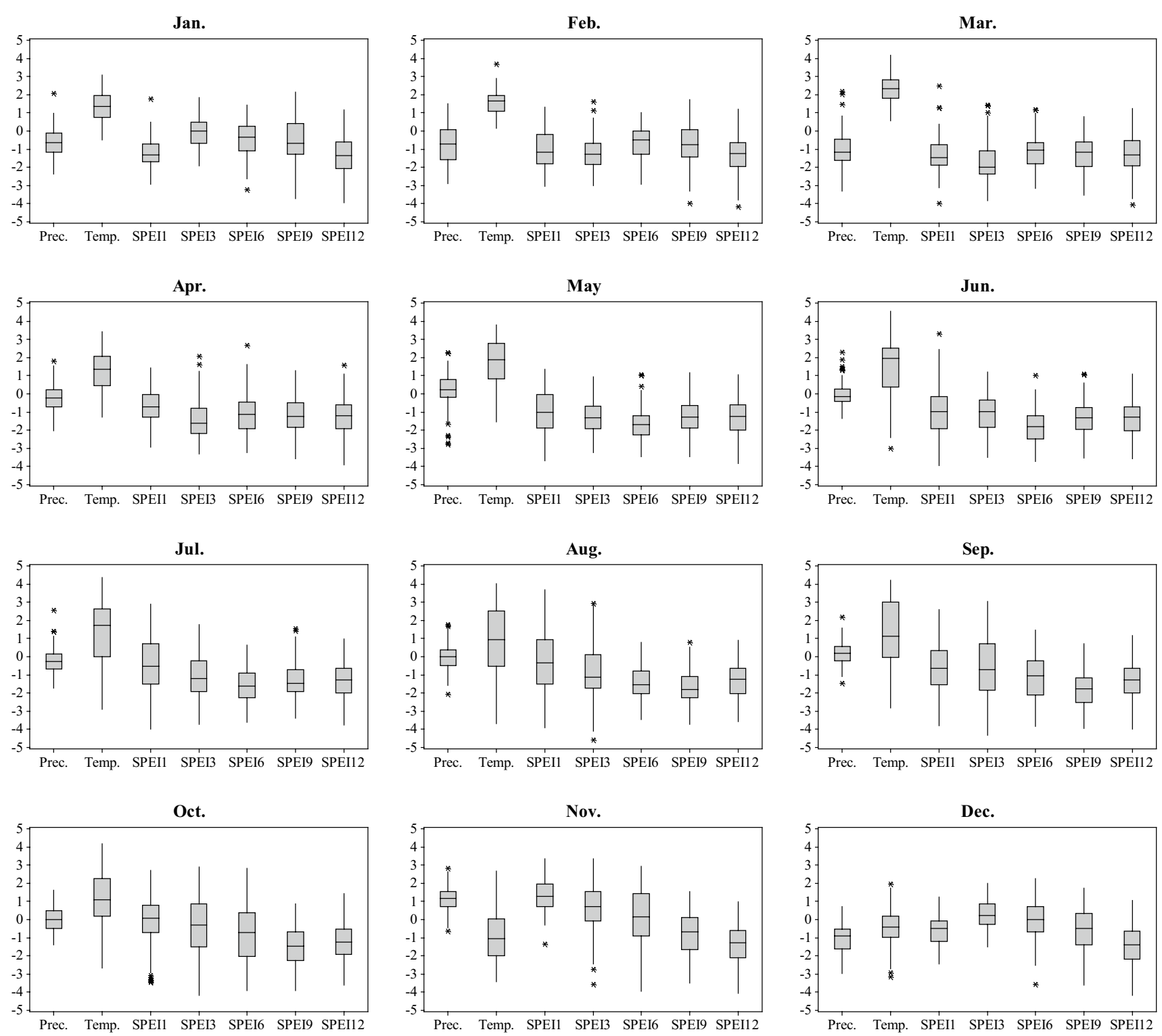

Fig. 4 Box plots of $Z_{M K}$ statistic depicting trends in 100 stations throughout the country

For mapping $\mathrm{PCs}$, factor loadings corresponding to each PC for each time scale were interpolated across the country. In Fig. 5, the spatial patterns of promax rotated loadings for the first five PCs on various time scales are shown. For all time scales, each of the five promax rotated loadings seems to represent a coherent and distinct region i.e. the northwestern (NW), the southwestern (SW), the southeastern (SE), the northern $(\mathrm{N})$ and the central/eastern (CE) parts. The number of stations belonging to each region in various time scales is provided in Table 2. Further, the temporal variability of PC scores associated with mapped loadings and trend analysis based on MK test are presented in Fig. 6 and Table 2.
Results show that the SPEl spatial patterns identified from factor loadings do not change with changing SPEI time scale. It means that throughout the accumulated periods, regions extents would be nearly identical. It seems that drought variability in each region depends on the region's climate type. Our analysis based on the Koppen climate classification showed that regions of $\mathrm{N}$, NW, SW, SE and CE are mostly very-humid, humid, subhumid, semi-arid and arid climates, respectively. The spatial behavior of the SPEI for various time scales reveals that the PCs' orders of importance are not the same in different regions. For instance, PC1, PC2, PC4, PC4 and PC4 associated with SPEI1, SPEI3, SPEI6, SPEI9 and SPEI12, respectively, identify the $C E$ region. Accordingly, spatial variability 

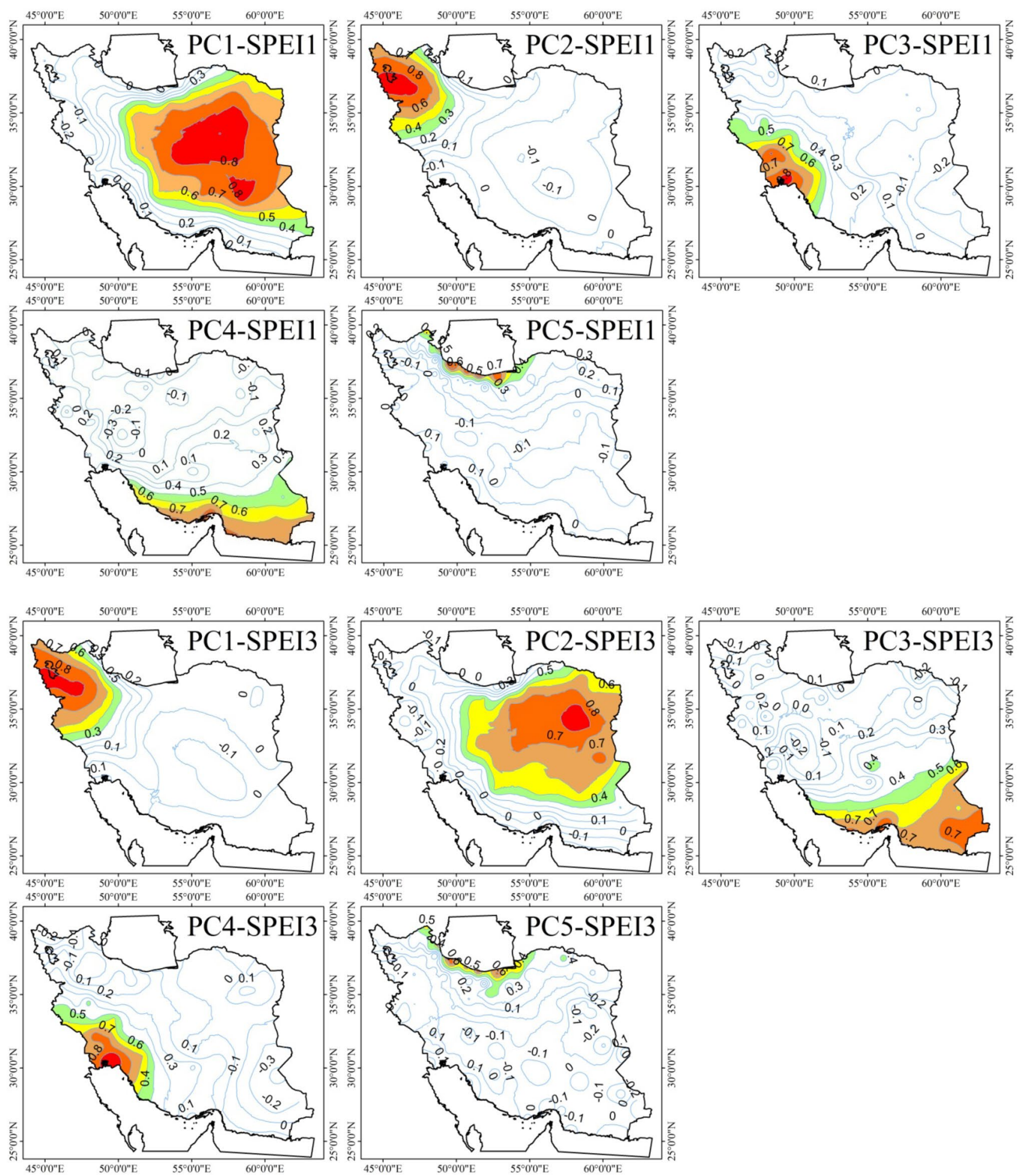

Fig. 5 Spatial patterns of promax rotated loadings for the first five PCs in various time scales

in the $\mathrm{CE}$ region decreases when time scale increases. In other words, short period droughts such as meteorological and agricultural droughts have higher spatial variability than hydrological drought.
The spatial pattern in the NW region appears unchanged when SPEI time scale varies from 3- to 12-month. The NW region is identified by PC1 for SPEI3 to SPEI12, while by PC2 for SPEI1. SW and SE varied from 

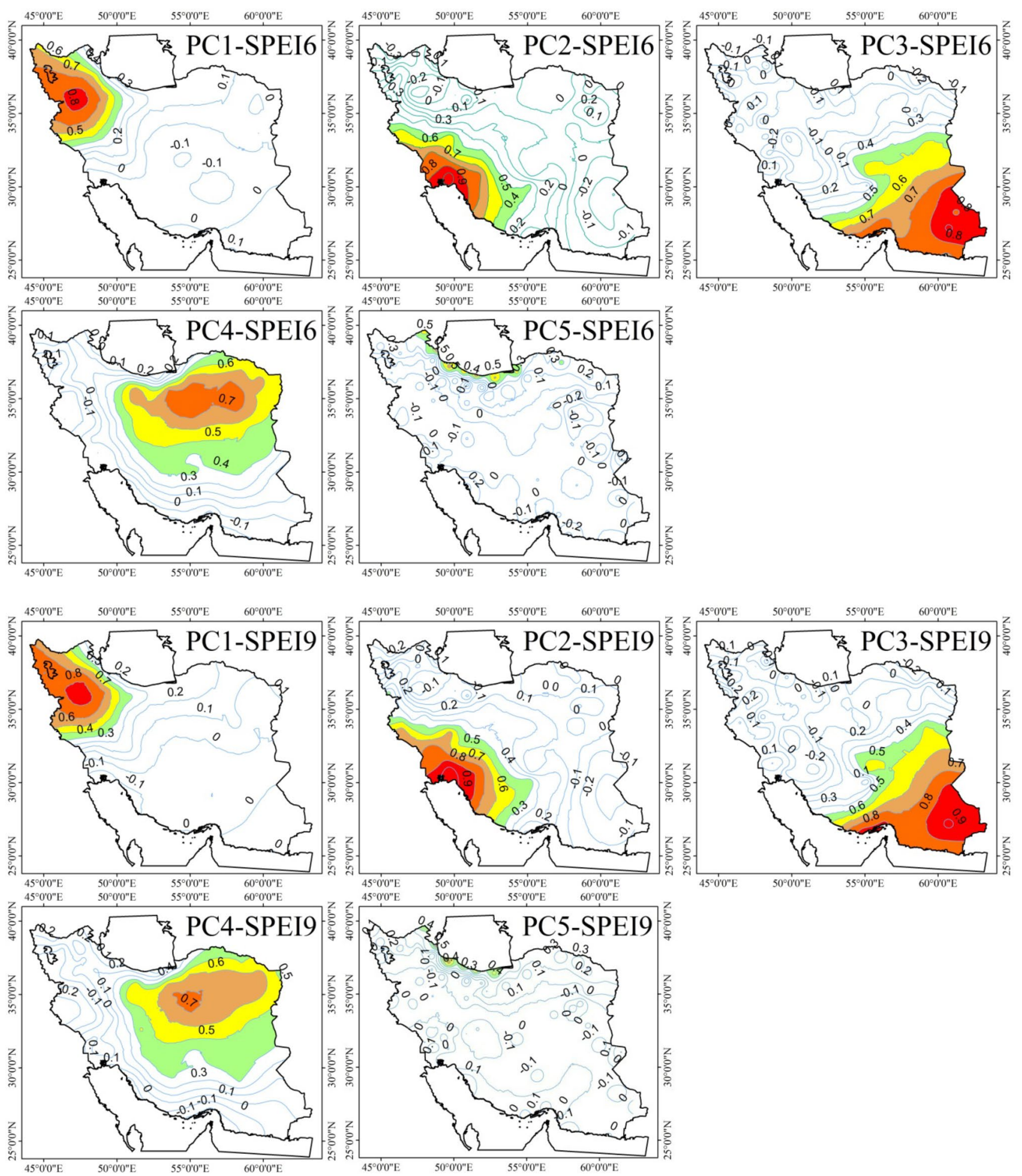

Fig. 5 (continued)

PC2 to PC4 for various time scales. SE region appears to be constantly identified by PC3 when SPEl time scale varies from 3- to 9-month. In the SE region, unlike CE region, long period droughts such as hydrological droughts have higher spatial variability than short period ones. The loadings associated with $\mathrm{PC} 5$, which is related to $\mathrm{N}$ region, appear to be spatially more homogeneous than other PCs for all time scales. It means that droughts in north 

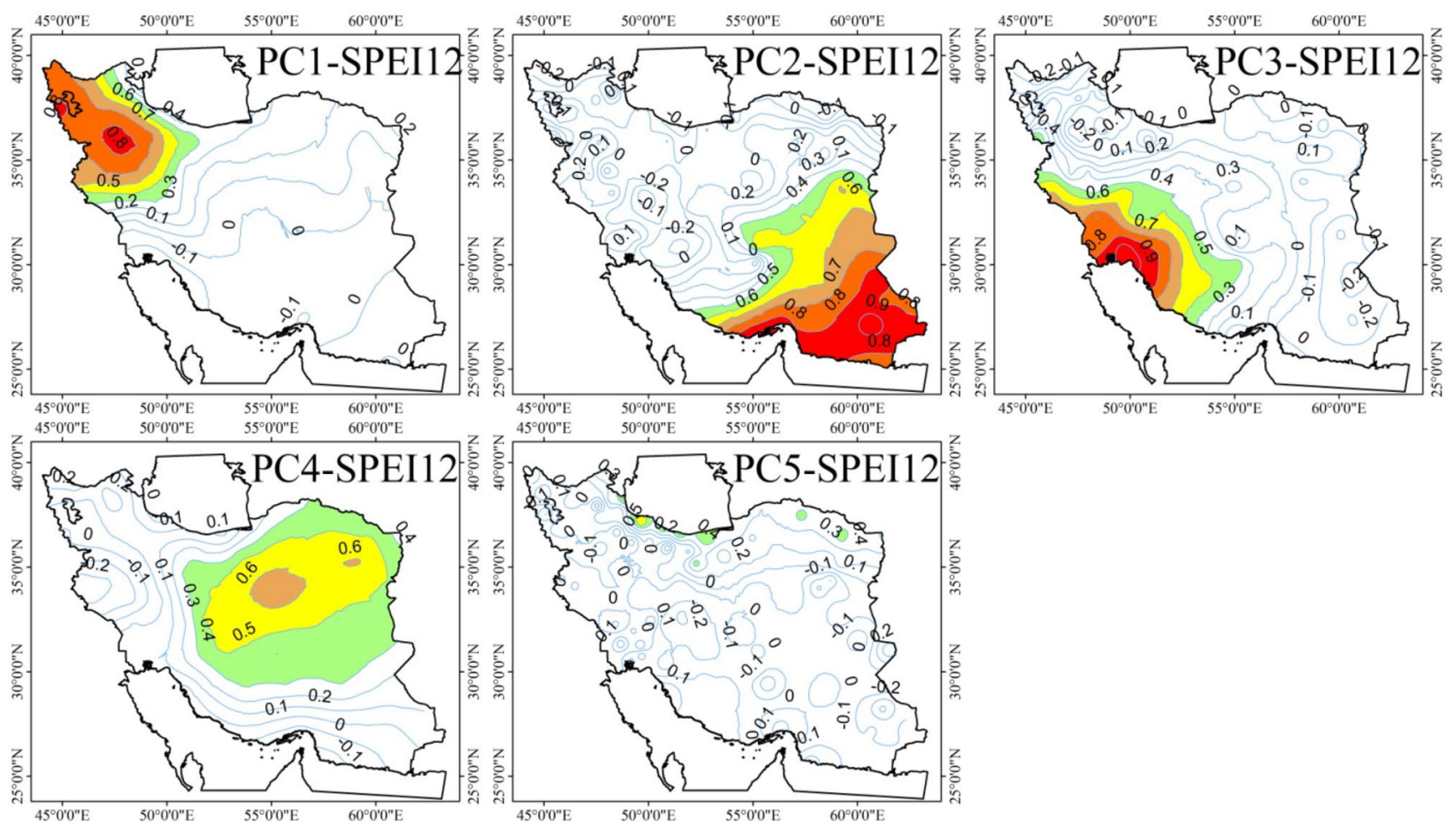

Fig. 5 (continued)

coastal region have lower spatial variability compared to other regions. Since precipitation in the $\mathrm{N}$ region has often an increasing trend based on the MK test, droughts might reflect the effects of increased temperature. Figure 5 shows that in the NW region, all types of droughts (meteorological, agricultural and hydrological) have similar spatial variabilities, while in the $C E, S W$ and SE regions spatial variability increases from meteorological to hydrological drought.

The temporal variabilities of the PC scores were examined for trend using the MK test. The PCs time series along with trend lines and the corresponding $Z$ values are presented in Fig. 6 and Table 2. Results show that temporal variabilities of the scores are statistically significant for all PCs and all time scales, except for PC3 and PC5 of SPEI1 that identified $S W$ and $N$ regions, respectively. With $Z$ values being negative in these regions, we may conclude that there is an evidence for long-term increasing trend of drought occurrences in all identified regions.

Table 2 shows that $Z$ values of the MK test in all regions, except in $S E$, increase when time scale increases. This is consistent with findings represented in Fig. 3. The most significant trends have occurred in SE region in all time scales with $Z$ values smaller than -7.0. This is likely due to the fact that $S E$ region has experienced the most significant increase in temperature and consequently ETP and the most significant decrease in precipitation. Unlike the spatial variability, the temporal variability of SPEls in the $\mathrm{N}$ region are similar to other regions. The significance of trends increases when time scale increases. Due to no or increasing trends in the observed precipitation in the $\mathrm{N}$, the drought exacerbation should be due to the temperature rise. Various researchers such as Sheffield and Wood [50], Dubrovsky et al. [12], Vicente-Serrano et al. [69] and Mathbout et al. [39] confirmed that drought severity may increase as a consequence of temperature rise which in turn produces a higher water demand by PET. This can have an effect on drought as high as precipitation shortage [1].

According to Fig. 6, temporal variabilities indicate some years with severe drought episodes. Based on the SPEI values, most of the drought episodes have occurred in the last two decades of the study period i.e. 1998-2017. This is in accord with Babaeian et al. [3] that reported a temperature increase and precipitation decrease in Iran.

The top three drought events ranked by their severities are reported in Table 3 for each region and time scale. In various regions, several episodes having remarkable negative values yield critical drought conditions for years 1998-2002, 2008-2011 and 2015-2017. The most severe drought event, with SPEI12 as high as -35.1 , occurred during 1999-2000 in NW region due to high rates of PET and low precipitation during a 22 months long episode. It can be seen that in all regions, most severe droughts 
Table 2 PC number and Z value corresponding with as well as number of stations falling into each region

\begin{tabular}{|c|c|c|c|c|c|}
\hline & NW & CE & SW & SE & $\mathrm{N}$ \\
\hline \multicolumn{6}{|l|}{ 1-month SPEI } \\
\hline PC num. & PC2 & PC1 & PC3 & PC4 & PC5 \\
\hline$Z$ value & -2.6653 & -2.5426 & -1.1996 & -7.2534 & -0.9647 \\
\hline $\begin{array}{l}\text { Num. of sta- } \\
\text { tions }\end{array}$ & 27 & 38 & 19 & 13 & 10 \\
\hline \multicolumn{6}{|l|}{ 3-month SPEI } \\
\hline PC num. & PC1 & PC2 & PC4 & PC3 & PC5 \\
\hline$Z$ value & -2.2884 & -2.6521 & -2.4198 & -8.3807 & -3.0668 \\
\hline $\begin{array}{l}\text { Num. of sta- } \\
\text { tions }\end{array}$ & 29 & 36 & 17 & 17 & 12 \\
\hline \multicolumn{6}{|l|}{ 6-month SPEI } \\
\hline PC num. & PC1 & PC4 & PC2 & PC3 & PC5 \\
\hline$Z$ value & -2.6188 & -3.5638 & -3.8978 & -7.7557 & -4.0731 \\
\hline $\begin{array}{l}\text { Num. of sta- } \\
\text { tions }\end{array}$ & 30 & 30 & 21 & 20 & 11 \\
\hline \multicolumn{6}{|l|}{ 9-month SPEI } \\
\hline PC num. & PC1 & PC4 & PC2 & PC3 & PC5 \\
\hline$Z$ value & -3.7321 & -5.1557 & -4.9532 & -7.6347 & -3.1509 \\
\hline $\begin{array}{l}\text { Num. of sta- } \\
\text { tions }\end{array}$ & 32 & 30 & 25 & 21 & 8 \\
\hline \multicolumn{6}{|l|}{ 12-month SPEI } \\
\hline PC num. & PC1 & PC4 & PC3 & PC2 & PC5 \\
\hline$Z$ value & -4.2379 & -4.7744 & -5.8359 & -7.9538 & -5.6729 \\
\hline $\begin{array}{l}\text { Num. of sta- } \\
\text { tions }\end{array}$ & 35 & 31 & 24 & 20 & 12 \\
\hline
\end{tabular}

have occurred during the last 15-20 years with exceptions to SW/SPEI9 (1994), SW/SPEI6 (1988-1989) and N/SPEI6 (1995). Moreover, the majority of extreme drought periods have happened in wet months (i.e. November-April) in all five regions.

\subsection{Risk analysis}

Drought severity and duration for all regions were calculated from time series of the SPEls. A significant correlation (higher than 0.7) was observed between drought severity and duration by the Pearson correlation coefficient, revealing that drought severity and duration are positively correlated and should be modeled jointly. The greatest correlation of 0.96 exists for SPEI3 in CE region, and the lowest value of 0.77 for SPEl1 in $\mathrm{N}$ region.

At first, univariate CDFs need to be separately fitted to drought severity and duration series extracted from drought events identified by the SPEI. The Kolmogorov-Smirnov (K-S) goodness-of-fit test should be applied to detect the best function that represents the marginal univariate CDF. It was found that among well-known functions, the gamma and the exponential distributions have suitable performance to model drought severity and duration for all regions. This is in agreement with findings of Shiau and Modarres [52] and Dodangeh et al. [11].

After fitting the marginal distribution functions to characteristics series, the copula-based risk analysis of droughts was carried out by constructing the copula joint severity-duration CDFs. Among five functions, the most appropriate of the five copula functions is identified for describing the dependence structure between the drought characteristics for each region and each time scale, separately. The parameters of copula functions were estimated using maximum likelihood $[35,36]$. Table 4 provides the AIC values of these functions for various regions and time scales. The lowest values that represent the best models are bolded. From Table 4, it can be observed that in most of the cases Clayton model is the best model in terms of AIC. After Clayton, Gumbel-Hougaard model performs better than other three copula models. For each region and time scale, the bivariate model with the lowest AIC value was used.

Figure 7 displays the surface plots of JCDF and JEP for Gumbel-Hougaard copula for SPEI12 in the NW region, as an example. The lower density for a given pair of duration and severity of a drought event and a region indicates frequent water deficit. For example, 12-month drought having severity of 10 and duration of 5 months had a JCDF equal to $0.251,0.234,0.318,0.323$ and 0.356 for NW, SE, SW, CE and N, respectively. In other words, there is a higher JEP for a given drought event in the SE region compared to other regions.

The conditional drought return periods can be derived using selected bivariate copulas and inter-arrival times. It was found that the waiting time between two consecutive drought episodes was longer than half a year with the smallest and greatest values equal to 0.665 and 3.845 years for time scales 1- and 12-month in N and NW regions, respectively.

In order to analyze copula behavior in dealing with long-term return periods, we randomly generated 1000 pairs of severity and duration using univariate CDFs. The results were interpolated to raster for tracing specific isolines using nearest neighbor technique. Figure 8 presents contour lines of conditional return periods of drought events for SPEI3 to SPEI12 for the NW region. The figure shows bivariate distributions of the return periods of 3,5 , 10,30 and 50 years. For example, conditional return period of drought severity equal to 8 given duration nearly equal to 6 months is almost 80, 12, 10 and 9 years for 3-, 6-, 9and 12-month SPEls, respectively.

It can be seen from Fig. 8 that when time scale increases, longer and more severe droughts occur more frequently. For instance, using SPEI3 to SPEI12, the NW region experiences once in 50 years a drought with severities of $8,16,20$ 


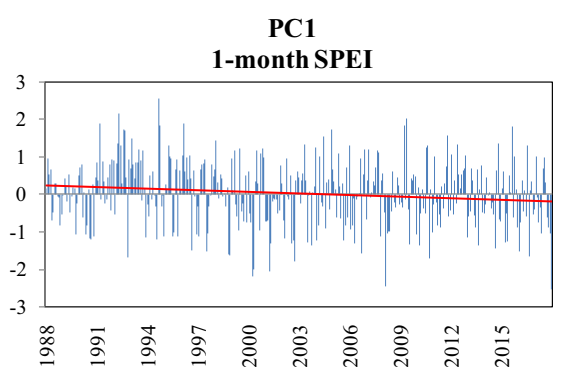

PC4

1-month SPEI

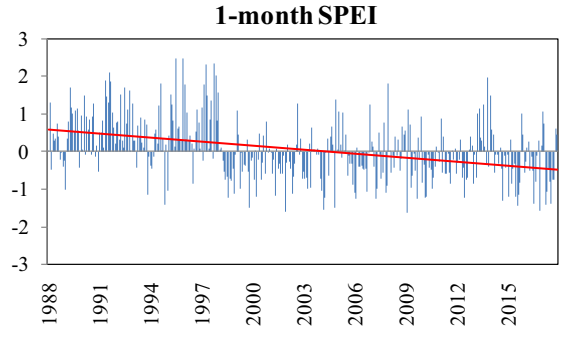

PC2

3-month SPEI

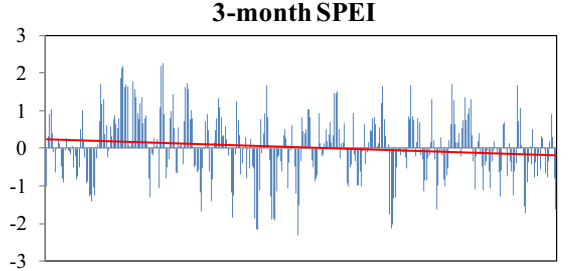

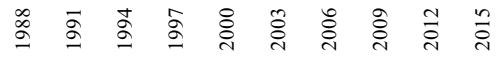

PC5

3-month SPEI

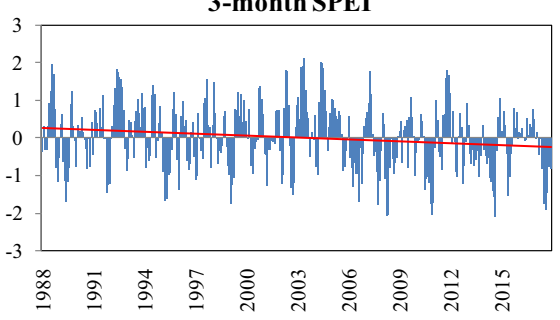

PC3

6-month SPE

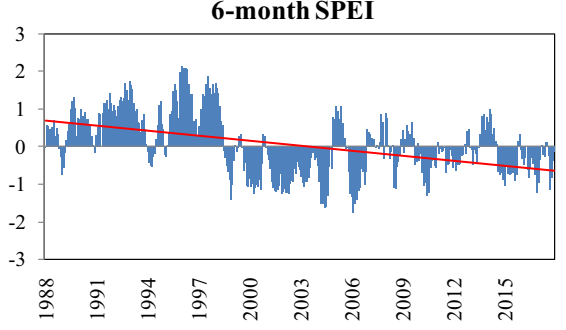

PC1

9-month SPEI

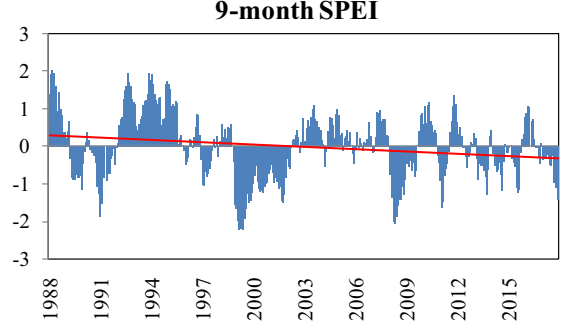

PC2

1-month SPEI

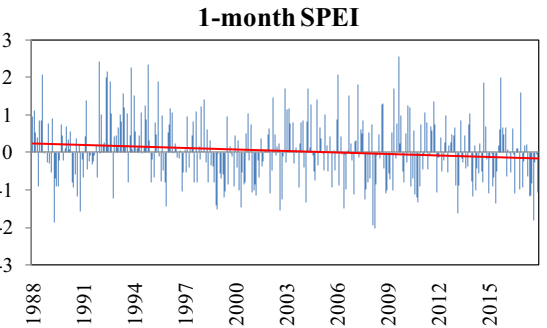

PC5

1-month SPEI

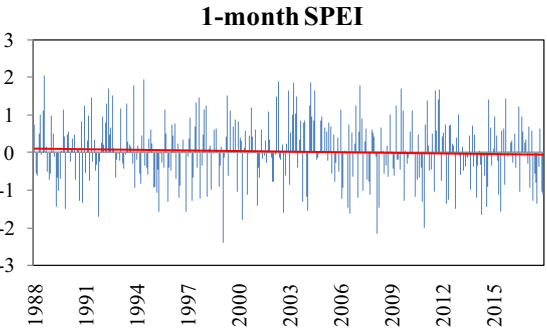

$\mathrm{PC} 3$

3-month SPEI

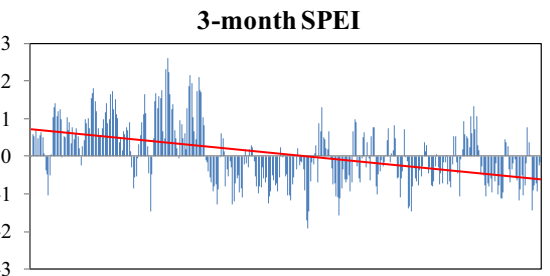

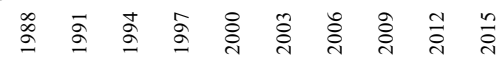

PC1

6-month SPEI

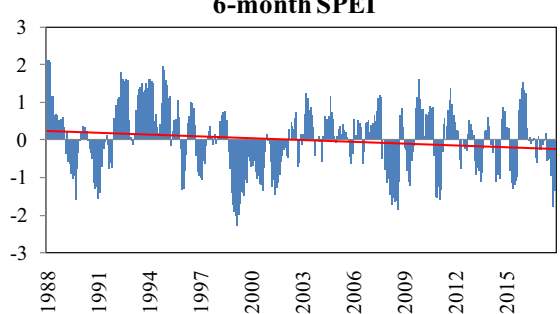

PC4

6-month SPEI

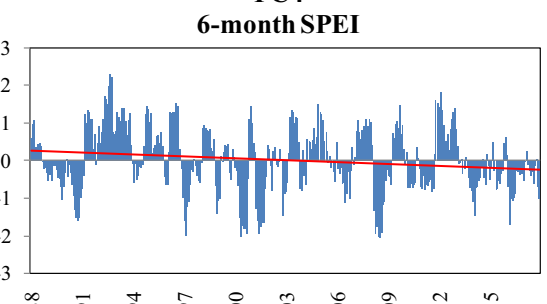

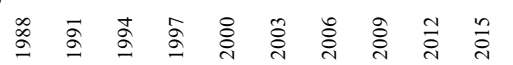

PC2

9-month SPEI

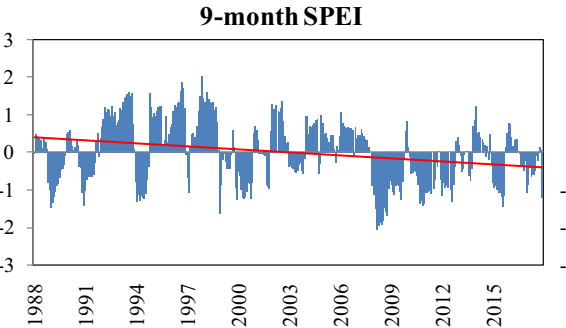

PC3

1-month SPEI

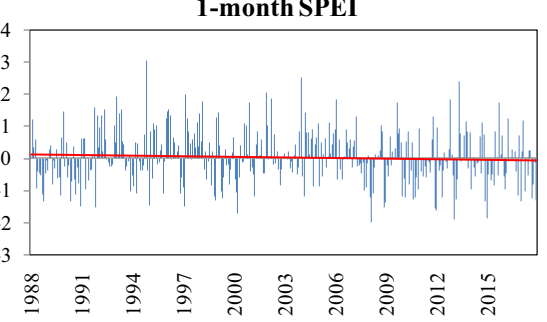

PC1

3-month SPEI

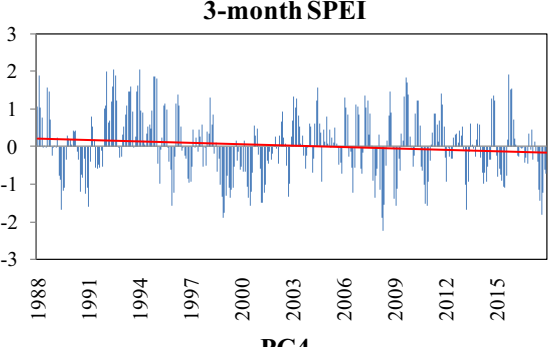

PC4

3-month SPEI

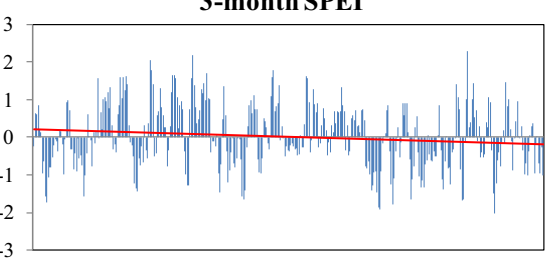

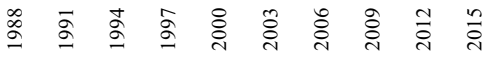
PC2 6-month SPEI

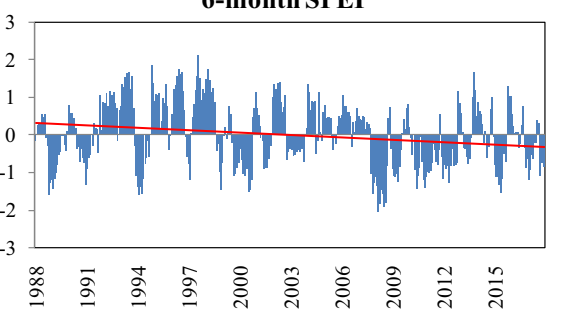

PC5

6-month SPEI

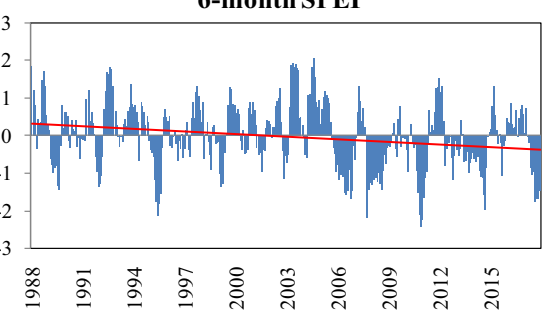

PC3

9-month SPEI

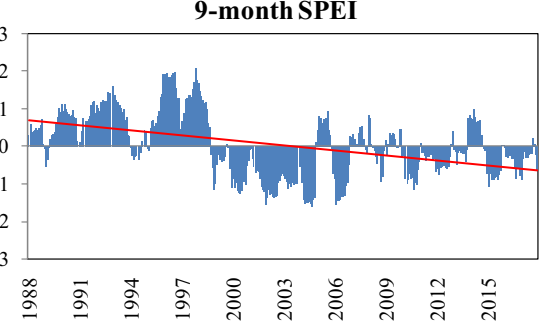

Fig. 6 Temporal variability of PC scores associated with mapped loadings 

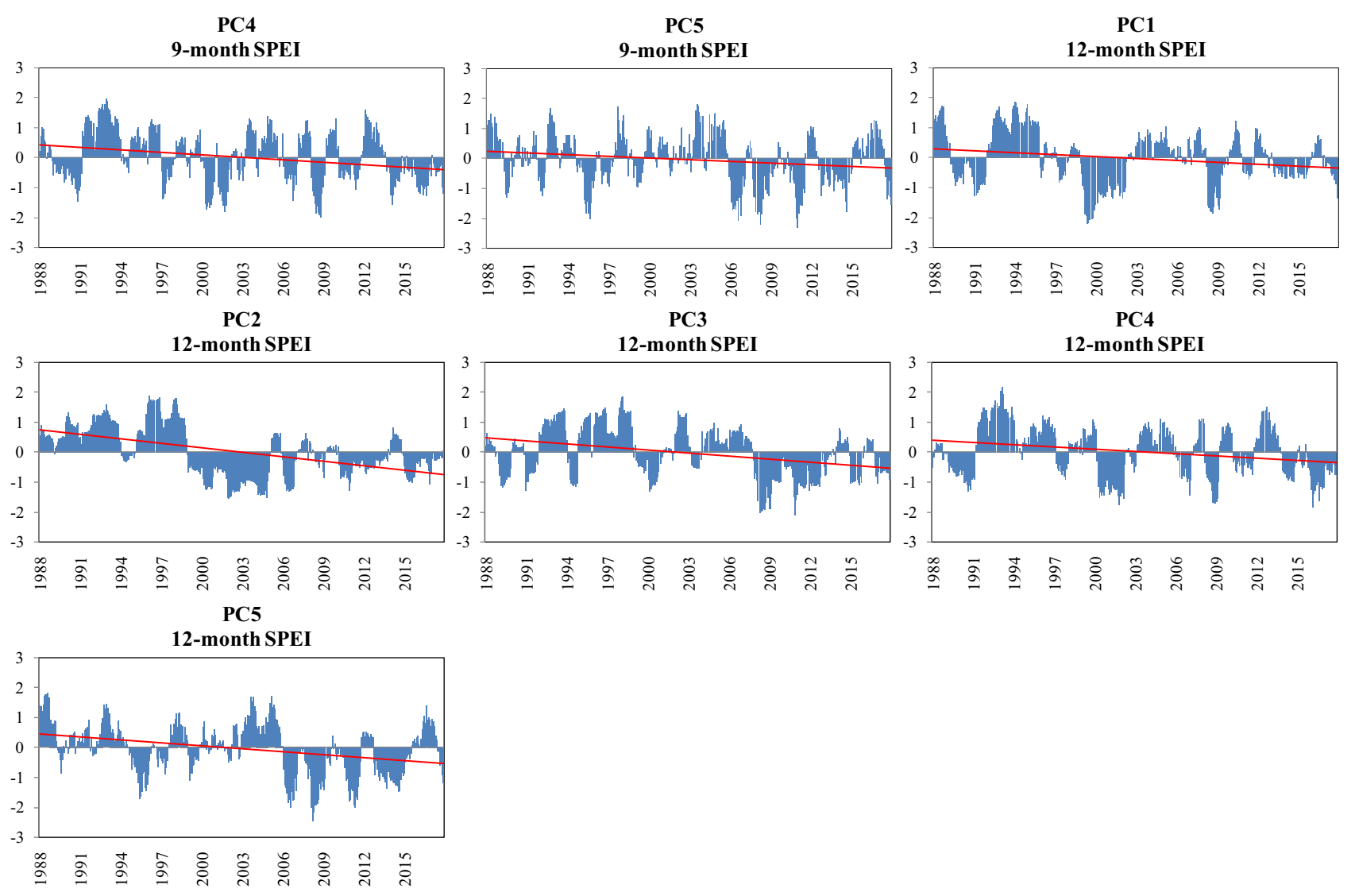

Fig. 6 (continued)

and 26 and durations of 5, 10, 12 and 17 months, respectively. Thus, the conditional return periods of drought characteristics derived from JCDFs can be useful in riskbased planning and management of various issues such as agriculture, water resources and economics in areas affected by drought.

We found patterns similar to those of Fig. 8 in all regions given inter-arrival time of droughts and JEP values. For the analysis of drought risk in various regions, five scenarios depicting an extreme event were also considered and the corresponding conditional return periods were intercompared. These scenarios are (1) duration of 1 and severity of 2 for SPEI1; (2) duration of 2 and severity of 4 for SPEI3; (3) duration of 3 and severity of 6 for SPEI6; (4) duration of 4 and severity of 8 for SPEI9; and (5) duration of 5 and severity of 10 for SPEI12. Table 5 reports the return periods for these scenarios in the five regions. Results indicate that the NW region is more susceptible to meteorological to hydrological droughts and can be categorized as a drought-prone region. The greatest drought showed in Table 3 has the return period greater than 100 years. This occurred in 1999 with duration of 22 month and severity of 35.1 and lasted to 2000 in the NW region. Among other four regions, short-term droughts recurred relatively more frequently in the CE and SW, whereas long-term droughts occurred relatively more frequently in $\mathrm{N}$ and $\mathrm{SE}$ regions. Although spatial variability of droughts is very low in the $\mathrm{N}$ region (Fig. 5), the return period of extreme events is as high as 5.4 to 13.1 years. As mentioned earlier, the more severe droughts in this region is mainly due to the increasing trend of temperature.

A high risk of extreme droughts is the greatest obstacle to the sustainable development and may hardly have recoverable impacts on agriculture and hydrology. The risk of extreme drought episodes with duration of 5 months over the country is once in 9 years, on average. Specifically, the NW region is subject to higher risk of droughts and experiences droughts with longer durations and higher severities. These conditions affect the water supply and may literally give rise to unprecedented challenges for agriculture and water resources management. 
Table 3 Top three drought events ranked by their severities

\begin{tabular}{|c|c|c|c|c|c|c|c|}
\hline Time scale & Rank & Feature & NW & CE & SW & SE & $\mathrm{N}$ \\
\hline \multirow[t]{9}{*}{ SPEI1 } & \multirow[t]{3}{*}{1} & Duration & 2 & 3 & 3 & 3 & 2 \\
\hline & & Severity & -4 & -4.4 & -4.3 & -3.9 & -3.6 \\
\hline & & $\mathrm{S}$ and $\mathrm{E}$ & $\begin{array}{l}\text { Apr. } 2008 \text { and May } \\
2008\end{array}$ & $\begin{array}{l}\text { Aug. } 2002 \text { and Oct. } \\
2002\end{array}$ & $\begin{array}{l}\text { Feb. } 2008 \text { and Apr. } \\
2008\end{array}$ & $\begin{array}{l}\text { Feb. } 2004 \text { and Apr. } \\
2004\end{array}$ & $\begin{array}{l}\text { Mar. } 2008 \text { and Apr. } \\
2008\end{array}$ \\
\hline & \multirow[t]{3}{*}{2} & Duration & 3 & 2 & 2 & 3 & 2 \\
\hline & & Severity & -3.7 & -4.2 & -3.2 & -3.8 & -3.3 \\
\hline & & $\mathrm{S}$ and $\mathrm{E}$ & $\begin{array}{l}\text { Sep. } 2010 \text { and Nov. } \\
2010\end{array}$ & $\begin{array}{l}\text { Apr. } 2000 \text { and May } \\
2000\end{array}$ & $\begin{array}{l}\text { Dec. } 2014 \text { and Jan. } \\
2015\end{array}$ & $\begin{array}{l}\text { Jul. } 2015 \text { and Sep. } \\
2015\end{array}$ & $\begin{array}{l}\text { Nov. } 2010 \text { and Dec. } \\
2010\end{array}$ \\
\hline & \multirow[t]{3}{*}{3} & Duration & 2 & 2 & 2 & 2 & 2 \\
\hline & & Severity & -2.9 & -3.5 & -3.2 & -2.5 & -2.7 \\
\hline & & $\mathrm{S}$ and $\mathrm{E}$ & $\begin{array}{l}\text { Nov. } 1998 \text { and Dec. } \\
1998\end{array}$ & $\begin{array}{l}\text { Mar. } 2008 \text { and Apr. } \\
2008\end{array}$ & $\begin{array}{l}\text { Dec. } 2011 \text { and Jan. } \\
2012\end{array}$ & $\begin{array}{l}\text { Apr. } 2017 \text { and May } \\
2017\end{array}$ & $\begin{array}{l}\text { Jan. } 2004 \text { and Feb. } \\
2004\end{array}$ \\
\hline \multirow[t]{9}{*}{ SPEI3 } & \multirow[t]{3}{*}{1} & Duration & 5 & 5 & 3 & 3 & 7 \\
\hline & & Severity & -7.4 & -8.6 & -5.3 & -5.1 & -10.1 \\
\hline & & $\mathrm{S}$ and $\mathrm{E}$ & $\begin{array}{l}\text { Oct. } 1998 \text { and Feb. } \\
1999\end{array}$ & $\begin{array}{l}\text { Mar. } 2008 \text { and Jul. } \\
2008\end{array}$ & $\begin{array}{l}\text { Mar. } 2008 \text { and May } \\
2008\end{array}$ & $\begin{array}{l}\text { Mar. } 2004 \text { and May } \\
2004\end{array}$ & $\begin{array}{l}\text { Jul. } 2010 \text { and Jan. } \\
2011\end{array}$ \\
\hline & \multirow[t]{3}{*}{2} & Duration & 4 & 5 & 4 & 4 & 5 \\
\hline & & Severity & -6.9 & -8.2 & -4.9 & -4.9 & -7.2 \\
\hline & & $\mathrm{S}$ and $\mathrm{E}$ & $\begin{array}{l}\text { Mar. } 2008 \text { and Jun. } \\
2008\end{array}$ & $\begin{array}{l}\text { Mar. } 2001 \text { and Jul. } \\
2001\end{array}$ & $\begin{array}{l}\text { Sep. } 2010 \text { and Dec. } \\
2010\end{array}$ & $\begin{array}{l}\text { Dec. } 2005 \text { and Mar. } \\
2006\end{array}$ & $\begin{array}{l}\text { May } 2014 \text { and Sep. } \\
2014\end{array}$ \\
\hline & \multirow[t]{3}{*}{3} & Duration & 4 & 4 & 3 & 3 & 3 \\
\hline & & Severity & -5.7 & -7.4 & -4.8 & -4.2 & -5.2 \\
\hline & & $\mathrm{S}$ and $\mathrm{E}$ & $\begin{array}{l}\text { Jul. } 2017 \text { and Oct. } \\
2017\end{array}$ & $\begin{array}{l}\text { Apr. } 2000 \text { and Jul. } \\
2000\end{array}$ & $\begin{array}{l}\text { Jan. } 2015 \text { and Mar. } \\
2015\end{array}$ & $\begin{array}{l}\text { Mar. } 2010 \text { and May } \\
2010\end{array}$ & $\begin{array}{l}\text { Mar. } 2008 \text { and May } \\
2008\end{array}$ \\
\hline \multirow[t]{9}{*}{ SPEI6 } & \multirow[t]{3}{*}{1} & Duration & 12 & 8 & 11 & 8 & 6 \\
\hline & & Severity & -19.4 & -13.3 & -16.9 & -11 & -11.1 \\
\hline & & $\mathrm{S}$ and $\mathrm{E}$ & $\begin{array}{l}\text { Nov. } 1998 \text { and Oct. } \\
1999\end{array}$ & $\begin{array}{l}\text { Mar. } 2008 \text { and Oct. } \\
2008\end{array}$ & $\begin{array}{l}\text { Oct. } 2007 \text { and Aug. } \\
2008\end{array}$ & $\begin{array}{l}\text { Dec. } 2005 \text { and Jul. } \\
2006\end{array}$ & $\begin{array}{l}\text { Oct. } 2010 \text { and Mar. } \\
2011\end{array}$ \\
\hline & \multirow[t]{3}{*}{2} & Duration & 9 & 6 & 6 & 6 & 5 \\
\hline & & Severity & -13.1 & -10.9 & -8.1 & -9.2 & -8.5 \\
\hline & & $\mathrm{S}$ and $\mathrm{E}$ & $\begin{array}{l}\text { Jan. } 2008 \text { and Sep. } \\
2008\end{array}$ & $\begin{array}{l}\text { Apr. } 2000 \text { and Sep. } \\
2000\end{array}$ & $\begin{array}{l}\text { Dec. } 1993 \text { and May } \\
1994\end{array}$ & $\begin{array}{l}\text { Mar. } 2004 \text { and Aug. } \\
2004\end{array}$ & $\begin{array}{l}\text { Apr. } 1995 \text { and Aug. } \\
1995\end{array}$ \\
\hline & \multirow[t]{3}{*}{3} & Duration & 5 & 6 & 5 & 7 & 5 \\
\hline & & Severity & -7.1 & -9.9 & -6.6 & -8.3 & -8 \\
\hline & & $\mathrm{S}$ and $\mathrm{E}$ & $\begin{array}{l}\text { Nov. } 2010 \text { and Mar. } \\
2011\end{array}$ & $\begin{array}{l}\text { Apr. } 2001 \text { and Sep. } \\
2001\end{array}$ & $\begin{array}{l}\text { Oct. } 1988 \text { and Feb. } \\
1989\end{array}$ & $\begin{array}{l}\text { Dec. } 2001 \text { and Jun. } \\
2002\end{array}$ & $\begin{array}{l}\text { Aug. } 2017 \text { and Dec. } \\
2017\end{array}$ \\
\hline \multirow[t]{9}{*}{ SPEI9 } & \multirow[t]{3}{*}{1} & Duration & 14 & 9 & 10 & 12 & 10 \\
\hline & & Severity & -24.1 & -14.5 & -17.1 & -15.5 & -16.2 \\
\hline & & $\mathrm{S}$ and $\mathrm{E}$ & $\begin{array}{l}\text { Dec. } 1998 \text { and Jan. } \\
2000\end{array}$ & $\begin{array}{l}\text { Apr. } 2008 \text { and Dec. } \\
2008\end{array}$ & $\begin{array}{l}\text { Jan. } 2008 \text { and Oct. } \\
2008\end{array}$ & $\begin{array}{l}\text { Sep. } 2001 \text { and Aug. } \\
2002\end{array}$ & $\begin{array}{l}\text { Feb. } 2006 \text { and Nov. } \\
2006\end{array}$ \\
\hline & \multirow[t]{3}{*}{2} & Duration & 9 & 8 & 10 & 9 & 9 \\
\hline & & Severity & -14.1 & -12.3 & -11.8 & -13.4 & -14.9 \\
\hline & & $\mathrm{S}$ and $\mathrm{E}$ & $\begin{array}{l}\text { Mar. } 2008 \text { and Nov. } \\
2008\end{array}$ & $\begin{array}{l}\text { Apr. } 2000 \text { and Nov. } \\
2000\end{array}$ & $\begin{array}{l}\text { Sep. } 2010 \text { and Jun. } \\
2011\end{array}$ & $\begin{array}{l}\text { Mar. } 2004 \text { and Nov. } \\
2004\end{array}$ & $\begin{array}{l}\text { Oct. } 2007 \text { and Jun. } \\
2008\end{array}$ \\
\hline & \multirow[t]{3}{*}{3} & Duration & 6 & 8 & 7 & 8 & 9 \\
\hline & & Severity & -6.8 & -11.6 & -8.4 & -10.9 & -14.4 \\
\hline & & $\mathrm{S}$ and $\mathrm{E}$ & $\begin{array}{l}\text { May } 2000 \text { and Oct. } \\
2000\end{array}$ & $\begin{array}{l}\text { May } 2001 \text { and Dec. } \\
2001\end{array}$ & $\begin{array}{l}\text { Feb. } 1994 \text { and Aug. } \\
1994\end{array}$ & $\begin{array}{l}\text { Feb. } 2006 \text { and Sep. } \\
2006\end{array}$ & $\begin{array}{l}\text { Nov. } 2010 \text { and Jul. } \\
2011\end{array}$ \\
\hline
\end{tabular}


Table 3 (continued)

\begin{tabular}{|c|c|c|c|c|c|c|c|}
\hline Time scale & Rank & Feature & NW & CE & SW & SE & $\mathrm{N}$ \\
\hline \multirow[t]{9}{*}{ SPEI12 } & \multirow[t]{3}{*}{1} & Duration & 22 & 15 & 13 & 17 & 13 \\
\hline & & Severity & -35.1 & -20.4 & -23 & -21.6 & -21.6 \\
\hline & & $\mathrm{S}$ and $\mathrm{E}$ & $\begin{array}{l}\text { Feb. } 1999 \text { and Nov. } \\
2000\end{array}$ & $\begin{array}{l}\text { Jan. } 2001 \text { and Mar. } \\
2002\end{array}$ & $\begin{array}{l}\text { Mar. } 2008 \text { and Mar. } \\
2009\end{array}$ & $\begin{array}{l}\text { Dec. } 2001 \text { and Apr. } \\
2003\end{array}$ & $\begin{array}{l}\text { Mar. } 2008 \text { and Mar. } \\
2009\end{array}$ \\
\hline & \multirow[t]{3}{*}{2} & Duration & 7 & 7 & 12 & 12 & 12 \\
\hline & & Severity & -11.7 & -10.7 & -15.6 & -15.9 & -18.6 \\
\hline & & $\mathrm{S}$ and $\mathrm{E}$ & $\begin{array}{l}\text { Apr. } 2008 \text { and Oct. } \\
2008\end{array}$ & $\begin{array}{l}\text { Aug. } 2008 \text { and Feb. } \\
2009\end{array}$ & $\begin{array}{l}\text { Nov. } 2010 \text { and Oct. } \\
2011\end{array}$ & $\begin{array}{l}\text { Dec. } 2003 \text { and Nov. } \\
2004\end{array}$ & $\begin{array}{l}\text { Sep. } 2010 \text { and Aug } \\
2011\end{array}$ \\
\hline & \multirow[t]{3}{*}{3} & Duration & 6 & 8 & 10 & 9 & 11 \\
\hline & & Severity & -7.2 & -10.5 & -11.2 & -10.9 & -17.2 \\
\hline & & $\mathrm{S}$ and $\mathrm{E}$ & $\begin{array}{l}\text { Oct. } 2001 \text { and Mar. } \\
2002\end{array}$ & $\begin{array}{l}\text { Apr. } 2000 \text { and Nov. } \\
2000\end{array}$ & $\begin{array}{l}\text { Jan. } 2012 \text { and Oct. } \\
2012\end{array}$ & $\begin{array}{l}\text { Mar. } 2006 \text { and Nov. } \\
2006\end{array}$ & $\begin{array}{l}\text { Mar. } 2006 \text { and Jan. } \\
2007\end{array}$ \\
\hline
\end{tabular}

Table 4 Comparison of performance of copula models based on the AIC

\begin{tabular}{|c|c|c|c|c|c|c|}
\hline Regions & Index & Clayton & Normal & Gumbel-Hougaard & $\mathrm{T}$ & Frank \\
\hline \multirow[t]{5}{*}{ NW } & SPEI1 & -21.0966 & -19.7874 & -19.0455 & -17.8819 & -17.0931 \\
\hline & SPEI3 & -31.619 & -44.1577 & -38.0219 & -41.4032 & -39.2383 \\
\hline & SPEI6 & -49.0714 & 6.964997 & -44.0663 & -30.4217 & -40.895 \\
\hline & SPEI9 & -50.6275 & -37.8066 & -43.2472 & -38.2792 & -37.7712 \\
\hline & SPEI12 & -19.5546 & -11.4992 & -20.0769 & -15.5481 & -14.9135 \\
\hline \multirow[t]{5}{*}{ CE } & SPEI1 & -20.9722 & -18.4901 & 13.07117 & 0.588818 & -12.8867 \\
\hline & SPEI3 & -33.312 & 33.03453 & -29.8577 & -5.79308 & -26.5537 \\
\hline & SPEI6 & -39.7906 & -31.8453 & -37.3027 & -32.599 & -35.8 \\
\hline & SPEI9 & -34.7984 & -11.9964 & -34.1602 & -21.4386 & -31.994 \\
\hline & SPEI12 & -8.55588 & -3.40151 & -17.4387 & -14.73 & -21.6957 \\
\hline \multirow[t]{5}{*}{ SW } & SPEI1 & -26.572 & 46.23396 & -23.567 & 9.350025 & -20.2298 \\
\hline & SPEI3 & -20.9991 & -25.5233 & -26.2439 & -24.904 & -31.6964 \\
\hline & SPEI6 & -46.6822 & 23.35107 & -39.967 & -27.0841 & -35.5579 \\
\hline & SPEI9 & -40.8548 & -31.7877 & -37.5356 & -32.8723 & -35.4265 \\
\hline & SPEI12 & -42.0352 & -29.686 & -34.6336 & -29.9528 & -30.5864 \\
\hline \multirow[t]{5}{*}{ SE } & SPEI1 & -11.4624 & 128.2812 & -10.0738 & 35.20817 & -5.88059 \\
\hline & SPEI3 & -18.0902 & 6.991249 & -16.6787 & -2.30672 & -15.3711 \\
\hline & SPEI6 & -34.7145 & 15.26338 & -31.3521 & -16.5134 & -28.5865 \\
\hline & SPEI9 & -25.3072 & 133.3029 & -20.8793 & -6.90253 & -17.2345 \\
\hline & SPEI12 & 13.23738 & 7.495991 & -23.073 & -19.4598 & -19.3425 \\
\hline \multirow[t]{5}{*}{$N$} & SPEI1 & -11.7386 & -1.33211 & -10.3835 & -1.49736 & -5.90864 \\
\hline & SPEI3 & -35.2657 & 83.27224 & -32.1713 & 0.326492 & -29.2362 \\
\hline & SPEI6 & -19.3224 & -29.9548 & -28.9782 & -29.3219 & -35.8115 \\
\hline & SPEI9 & -40.0297 & 62.94654 & -35.0732 & -15.9546 & -31.7163 \\
\hline & SPEI12 & -36.1674 & -18.0209 & -29.9282 & -25.6453 & -26.4269 \\
\hline
\end{tabular}

\section{Conclusion}

In this study, droughts in Iran were investigated using monthly precipitation and temperature time series obtained from 100 synoptic stations for the period
1987-2017. We employed the kernel density estimator instead of the three-parameter log-logistic distribution for estimating the CDFs of the monthly aggregated water deficit or surplus due to its simplicity and its accuracy in estimating frequencies of drought classes. Based on the trend analysis, we found a universal intensification 

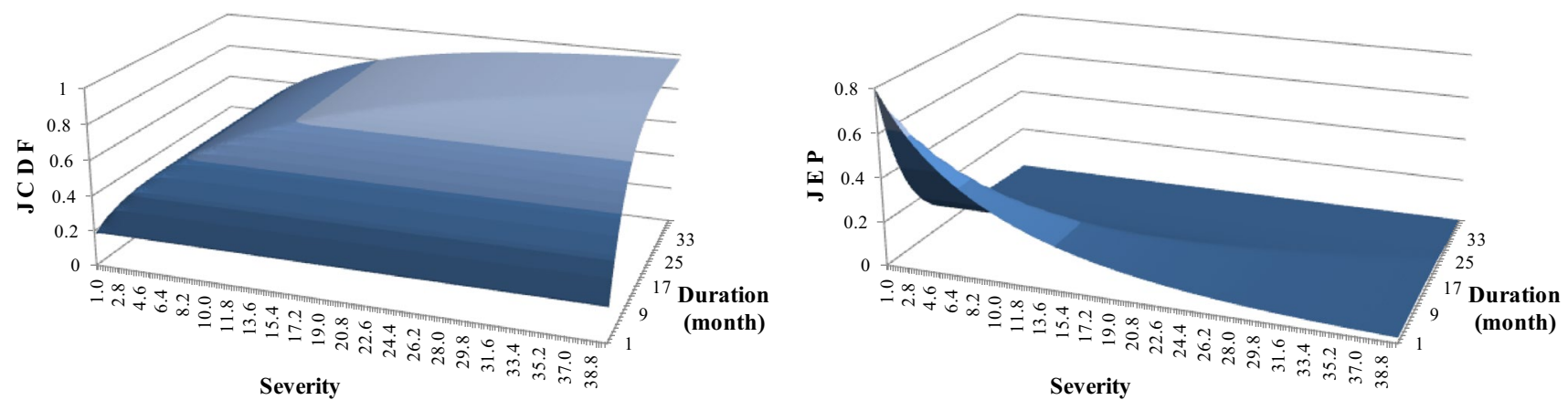

Fig. 7 Surface plots of JCDF and JEP of Gumbel-Hougaard copula for the NW region and 12-month SPEI

SPEI 3

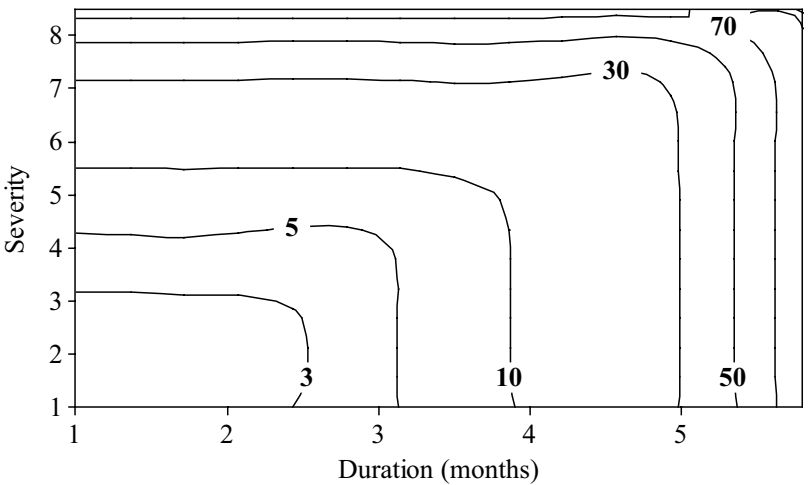

SPEI 9

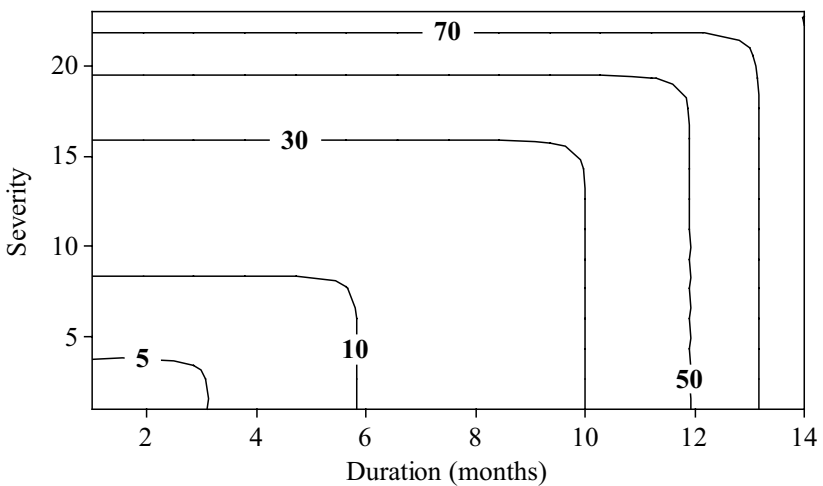

SPEI 6

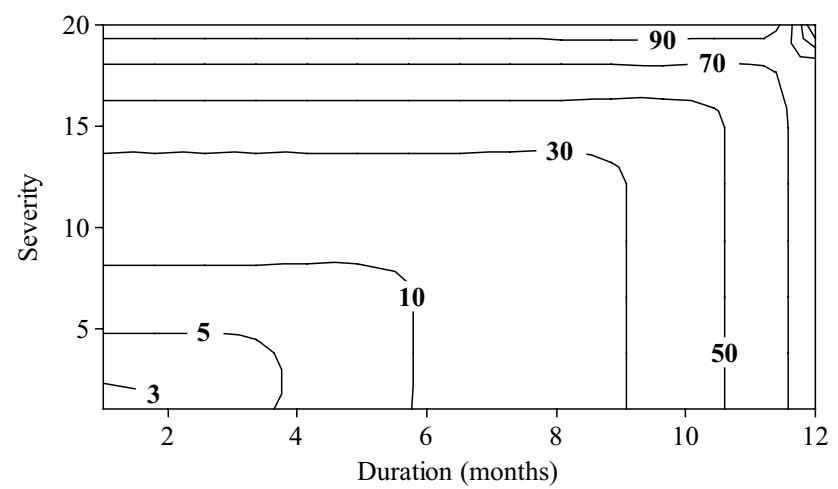

SPEI 12

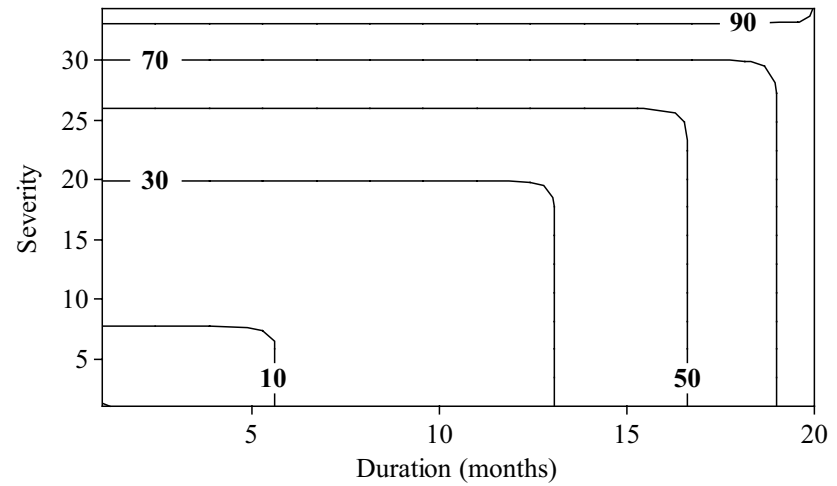

Fig. 8 Contour lines of conditional return periods (time unit is year) of drought events for 3- to 12-month SPEI in the NW region, as an example

Table 5 Return periods for five scenarios in five regions (years)

\begin{tabular}{lrlrlr}
\hline Scenario & NW & CE & SW & SE & N \\
\hline 1 & 3.5 & 3.9 & 3.2 & 6.6 & 5.4 \\
2 & 4.5 & 5.4 & 4.7 & 12.7 & 5.4 \\
3 & 6.6 & 8.7 & 8.8 & 8 & 6.7 \\
4 & 9.5 & 12 & 12.4 & 7.1 & 9.8 \\
5 & 11.9 & 11.8 & 12.2 & 13.8 & 13.1 \\
\hline
\end{tabular}

of drought throughout the country, especially on long time scales. This occurs when there is a high difference between monthly precipitation with a considerable decreasing trend and a PET with a considerable increasing trend [25, 77]. According to Babaeian et al. [3]; in two recent decades, Iran has been influenced by the global warming along with decreasing rainfall. Although, the monthly water balance (SPEI1) of almost $45 \%$ of the 
stations has no negative significant trend, the accumulated water balance shows a large deficit in more stations due to climate change. Hence, drought monitoring should focus on the regions with decreasing trend in the accumulated water balance, since a considerable rise in PET may also lead to a drier soil condition even though precipitation have no significant decreasing trend [8]. Thereafter, by identifying the principle components of SPEI time series on different timescales, we identified five regions with different spatio-temporal behavior of drought. From the methodology and the results presented in this study, it can be concluded that the SPEI seems to be a reasonable index for description of Iran's droughts. Using SPEI on a regional scale, we found that the longest and most severe drought episodes have occurred in the last 15-20 years. Furthermore, northwestern region of Iran had the highest risk of drought based on the multi-dimensional copula. This study was a forward step in considering an aggregative perspective of meteorological, agricultural and hydrological water deficit. According to our findings, there is an urgent need to plan short-term/long-term strategies for encountering an efficacious development of drought early-warning systems for mitigating drought impacts on economic, social and environmental sustainability. This study enables decision makers to develop drought early-warning systems for each region separately, established using simplified mathematical predictors such as teleconnection indices.

\section{Compliance with ethical standards}

Conflict of interests The authors declare that they have no conflict of interest.

\section{References}

1. Abramopoulos F, Rosenzweig C, Choudhury B (1988) Improved ground hydrology calculations for global climate models (GCMs): soil water movement and evapotranspiration. J Clim 1:921-941

2. Abramson IS (1982) On bandwidth variation in kernel estimates-a square root law. Ann Stat 10:1217-1223

3. Babaeian I, Modirian R, Karimian M, Zarghami M (2015) Simulation of climate change in Iran during 2071-2100 using PRECIS regional climate modelling system. Desert 20(2):123-134

4. Barua S (2010) Drought assessment and forecasting using a nonlinear aggregated drought index. Ph.D. Thesis, School of Engineering and Science Faculty of Health, Engineering and Science Victoria University, Australia

5. Bazrafshan J (2017) Effect of air temperature on historical trend of long-term droughts in different climates of Iran. Water Resour Manag 31:4683-4698. https://doi.org/10.1007/s1126 9-017-1773-8
6. Chen D, Gao G, Xu CY, Guo J, Ren G (2005) Comparison of the Thornthwaite method and pan data with standard PenmanMonteith estimates of reference evapotranspiration in China. Clim Res 28:123-132

7. Chen HP, Sun JQ (2015) Drought response to air temperature change over China on the centennial scale. Atmos Oceanic Sci Lett 8:113-119. https://doi.org/10.3878/AOSL20140089

8. Dai A (2013) Increasing drought under global warming in observations and models. Nat Clim Chang 3:52-58

9. Das PK, Dutta D, Sharma JR, Dadhwal VK (2016) Trends and behaviour of meteorological drought (1901-2008) over Indian region using standardized precipitation-evapotranspiration index. Int J Climatol 36:909-916

10. Dinardo J, Tobis L (2001) Nonparametric density and regression estimation. J Econ Perspect 15(4):11-28

11. Dodangeh E, Shahedi K, Shiau JT, Mirakbari M (2017) Spatial hydrological drought characteristics in Karkheh River basin, southwest Iran using copulas. J Earth Syst Sci 126(80):1-20

12. Dubrovsky M, Svoboda MD, Trnka M, Hayes MJ, Wilhite DA, Zalud Z, Hlavinka P (2008) Application of relative drought indices in assessing climate-change impacts on drought conditions in Czechia. Theor Appl Climatol 96:155-171

13. Farahmand A, AghaKouchak A (2015) A generalized framework for deriving nonparametric standardized drought indicators. Adv Water Resour 76:140-145

14. Frank A, Armenski T, Gocic M, Popov S, Popovic L, Trajkovic S (2017) Influence of mathematical and physical background of drought indices on their complementarity and drought recognition ability. Atmos Res 194:268-280

15. Ganguli P, Reddy MJ (2012) Risk assessment of droughts in Gujarat using bivariate copulas. Water Resour Manag 26:3301-3327

16. Gocic M, Trajkovic S (2014) Spatiotemporal characteristics of drought in Serbia. J Hydrol 510:110-123

17. Graler B, van den Berg M, Vandenberghe $S$, Petroselli A, Grimaldi S, Baets BD, Verhoest N (2013) Multivariate return periods in hydrology: a critical and practical review focusing on synthetic design hydrograph estimation. Hydrol Earth Syst Sci 17:1281-1296

18. Hamed KH (2009) Exact distribution of the Mann-Kendall trend test statistic for persistent data. J Hydrol 365:86-94

19. Hao Z, AghaKouchak A (2014) A nonparametric multivariate multi-index drought monitoring framework. J Hydrometeorol 15(1):89-101

20. Hayes MJ, Svoboda MD, Wilhite DA, Vanyarkho OV (1999) Monitoring the 1996 drought using the standardized precipitation index. Bull Am Meteorol Soc 80(3):429-437

21. Hayes MJ (2000) Revisiting the SPI: clarifying the process. Drought Netw News 1:13-14

22. Hendrickson AE, White PO (1964) Promax: a quick method for rotation to oblique simple structure. Br J Math Stat Psychol 17:65-70

23. Homdee T, Pongput $K$, Kanae $S$ (2016) A comparative performance analysis of three standardized climatic drought indices in the Chi River basin, Thailand. Agric Nat Resour 50:211-219

24. Huang S, Huang Q, Chang J, Zhu Y, Leng G, Xing L (2015) Drought structure based on a nonparametric multivariate standardized drought index across the Yellow River basin, China. J Hydrol 530:127-136

25. Hui-Mean F, Yusop Z, Yusof F (2018) Drought analysis and water resource availability using standardized precipitation evapotranspiration index. Atmos Res 201:102-115

26. IPCC (2013) Summary for policymakers, in climate change. In: Stocker TF, Qin D, Plattner GK, Tignor M, Allen SK, Boschung J, Nauels A, Xia Y, Bex V, Midgley PM (eds) The physical science basis. Contribution of working group I to the fifth assessment 
report of the intergovernmental panel on climate change. Cambridge University Press, Cambridge

27. Jensen ME, Burman RD, Allen RG (1990) Evapotranspiration and irrigation water requirements. In: ASCE manual of practice 70

28. Jiang R, Xie J, He H, Luo J, Zhu J (2015) Use of four drought indices for evaluating drought characteristics under climate change in Shaanxi, China: 1951-2012. Nat Hazards 75(3):2885-2903

29. Kendall MG (1975) Rank correlation methods. Griffin, London

30. Keyantash J, Dracup JA (2002) The quantification of drought: an analysis of drought indices. Bull Am Meteorol Soc 83(8):1167-1180

31. Kim D, Rhee J (2016) A drought index based on actual evapotranspiration from the Bouchet hypothesis. Geophys Res Lett 43:10-277. https://doi.org/10.1002/2016GL070302

32. Lang D, Zheng J, Shi J, Liao F, Ma X, Wang W, Chen X, Zhang M (2017) A comparative study of potential evapotranspiration estimation by eight methods with FAO Penman-Monteith method in southwestern China. Water 9:734-751

33. Li X, He B, Quan X, Liao Z, Bai X (2015) Use of the standardized precipitation evapotranspiration index (SPEI) to characterize the drying trend in southwest China from 1982-2012. Remote Sens 7(8):10917-10937. https://doi.org/10.3390/rs70810917

34. Li B, Liang Z, Zhang J, Wang G (2017) A revised drought index based on precipitation and pan evaporation. Int J Climatol 37:793-801

35. Liu S, Kang W, Wang T (2016) Drought variability in Inner Mongolia of northern China during 1960-2013 based in standardized precipitation evapotranspiration index. Environ Earth Sci 75:145. https://doi.org/10.1007/s12665-015-4996-0

36. Liu XF, Wang SX, Zhou Y, Wang FT, Yang G, Liu WL (2016) Spatial analysis of meteorological drought return periods in China using Copulas. Nat Hazards 80:367-388

37. Lo Conti F, Hsu KL, Noto LV, Sorooshian S (2014) Evaluation and comparison of satellite precipitation estimates with reference to a local area in the Mediterranean Sea. Atmos Res 138:189-204. https://doi.org/10.1016/j.atmosres.2013.11.011

38. Mann HB (1945) Nonparametric tests against trend. Econometrica 13:245-259

39. Mathbout S, Lopez-Bustins JA, Martin-Vide J, Bech J, Rodrigo FS (2018) Spatial and temporal analysis of drought variability at several time scales in Syria during 1961-2012. Atmos Res 200:153-168

40. Martins DS, Raziei T, Paulo AA, Pereira LS (2012) Spatial and temporal variability of precipitation and drought in Portugal. Nat Hazards Earth Syst Sci 12(5):1493-1501

41. McKee TB, Doesken NJ, Kleist J (1993) The relationship of drought frequency and duration to time scales. In: Proceeding of the 8th conference on applied climatology. American Meteorological Society, Boston, pp 179-184

42. Mishra AK, Singh VP (2010) A review of drought concepts. J Hydrol 391:202-216

43. Moreira EE (2015) SPI drought class prediction using log-linear models applied to wet and dry seasons. Phys Chem Earth Parts A/B/C. https://doi.org/10.1016/j.pce.2015.10.019

44. North GR, Bell TL, Cahalan RF, Moeng FJ (1982) Sampling errors in the estimation of empirical orthogonal functions. Mon Wearther Rev 110(7):699-706

45. Ozelkan E, Chen G, Ustundag BB (2016) Multiscale object-based drought monitoring and comparison in rainfed and irrigated agriculture from Landsat 8 OLI imagery. Int J Appl Earth Obs Geoinf 44:159-170

46. Palmer WC (1965) Meteorological drought, research paper no. 45. U.S. Department of Commerce Weather Bureau, Washington, DC, p 59
47. Rajagopalan B, Lall U, Tarboton DG (1997) Evaluation of kernel density estimation methods for daily precipitation resampling. Stoch Hydrol Hydraul 11:523-547

48. Santos JF, Pulido-Calvo I, Portela MM (2010) Spatial and temporal variability of droughts in Portugal. Water Resour Res 46:W03503. https://doi.org/10.1029/2009WR008071

49. Sharma A, Lall U, Tarboton DG (1998) Kernel bandwidth selection for a first order nonparametric streamflow simulation model. Stoch Hydrol Hydraul 12:35-52

50. Sheffield J, Wood EF (2008) Projected changes in drought occurrence under future global warming from multi-model, multiscenario, IPCC AR4 simulations. Clim Dyn 31:79-105

51. Shiau JT (2006) Fitting drought duration and severity with twodimensional Copulas. Water Resour Manag 20:795-815

52. Shiau JT, Modarres R (2009) Copula-based drought severityduration-frequency analysis in Iran. Meteorol Appl 16:481-489

53. Sienz F, Bothe O, Fraedrich K (2012) Monitoring and quantifying future climate projections of dryness and wetness extremes: SPI bias. Hydrol Earth Syst Sci 16(7):2143-2157

54. Silverman BW (1986) Density estimation for statistics and data analysis. Chapman and Hall, New York

55. Sklar A (1959) Fonctions de répartition á $\mathrm{n}$ dimensions et leurs marges. Publ Inst Stat Univ Paris 8:229-231

56. Smakhtin VU, Hughes DA (2004) Review, automated estimation and analysis of drought indices in South Asia. In: Working paper 83, International Water Management Institute, Sri Lanka

57. Smith LI (2002) A tutorial on principal components analysis. In: Computer sciences 26, University of Otago, Dunedin, New Zealand

58. Soláková T, De Michele C, Vezzoli R (2013) Comparison between parametric and nonparametric approaches for the calculation of two drought indices: SPI and SSI. J Hydrol Eng 19(9):04014010

59. Stagge JH, Tallaksen LM, Gudmundsson L, Loon AFV, Stahl K (2015) Candidate distributions for climatological drought indices (SPI and SPEI). Int J Climatol 35:4027-4040

60. Tan C, Yang J, Li M (2015) Temporal-spatial variation of drought indicated by SPI and SPEI in Ningxia Hui Autonomous Region, China. Atmosphere 6:1399-1421. https://doi.org/10.3390/atmos 6101399

61. Tigkas D, Vangelis H, Tsakiris G (2012) Drought and climatic change impact on stream-flow in small watersheds. Sci Total Environ 440:33-44

62. Thornthwaite CW (1948) An approach toward a rational classification of climate. Geogr Rev 38:55-94

63. UNEP (1992) World atlas of desertification

64. van der Schrier G, Jones PD, Briffa KR (2011) The sensitivity of the PDSI to the Thornthwaite and Penman-Monteith parameterizations for potential evapotranspiration. J Geophys Res 116:D03106. https://doi.org/10.1029/2010JD015001

65. Vicente-Serrano SM (2006) Differences in spatial patterns of drought on different time scales: an analysis of the Iberian Peninsula. Water Resour Manag 20:37-60

66. Vicente-Serrano SM, Gonzalez-Hidalgo JC, de Luis M, Raventos J (2004) Spatial and temporal patterns of droughts in the Mediterranean area: the Valencia region (East Spain). Clim Res 26:5-15

67. Vicente-Serrano SM, Beguería S, López-Moreno Jl (2010) A multiscalar drought index sensitive to global warming: the standardized precipitation evapotranspiration index. J Clim 23:1696-1718

68. Vicente-Serrano SM, Beguería S, López-Moreno Jl, Angulo M, Kenawy AE (2010) A new global 0.5 degrees gridded dataset (1901-2006) of a multiscalar drought index: comparison with current drought index datasets based on the Palmer drought severity index. J Hydrometeorol 11:1033-1043

69. Vicente-Serrano SM, Lopez-Moreno JI, Begueria S, LorenzoLacruz J, Sanchez-Lorenzo A, Garcia-Ruiz JM, Azorin-Molina C, 
Moran-Tejeda E, Revuelto J, Trigo R (2014) Evidence of increasing drought severity caused by temperature rise in southern Europe. Environ Res Lett 9:1-9

70. Vicente-Serrano SM, Miralles DiegoGonzalez, Domínguez-Castro Fernando, AzorinMolina Cesar, Kenawy El, Ahmed McVicar, Tim R, Tomás-Burguera Miquel, Beguería Santiago, Maneta Marco, Peña-Gallardo Marina (2018) Global assessment of the standardized evapotranspiration deficit index (SEDI) for drought analysis and monitoring. J Clim 31(14):5371-5393

71. Wang W, Zhu Y, Xu R, Liu J (2015) Drought severity change in China during 1961-2012 indicated by SPI and SPEI. Nat Hazards 75:2437-2451

72. Wang Y, Xu Y, Lei C, Li G, Han L, Song S, Yang L, Deng X (2016) Spatio-temporal characteristics of precipitation and dryness/ wetness in Yangtze River Delta, eastern China, during 19602012. Atmos Res 172:196-205

73. Wang H, Pan Y, Chen Y (2017) Comparison of three drought indices and their evolutionary characteristics in the arid region of northwestern China. Atmos Sci Lett 18:132-139

74. Waseem M, Ajmal M, Kim TW (2015) Development of a new composite drought index for multivariate drought assessment. J Hydrol 527:30-37

75. White D, Richman M, Yarnal B (1991) Climate regionalization and rotation of principal components. Int J Climatol 11:1-25

76. Willmott CJ, Rowe CM, Mintz Y (1985) Climatology of the terrestrial seasonal water cycle. J Climatol 5:589-606. https://doi. org/10.1002/joc.3370050602

77. Xu K, Yang D, Yang H, Li Z, Qin Y, Shen Y (2015) Spatio-temporal variation of drought in China during 1961-2012: a climatic perspective. J Hydrol 526:253-264. https://doi.org/10.1016/j.jhydr ol.2014.09.047

78. Yao J, Zhao Y, Yu X (2018) Spatial-temporal variation and impacts of drought in Xinjiang (Northwest China) during 1961-2015. PeerJ 6:e4926. https://doi.org/10.7717/peerj.4926
79. Yang J, Wang Y, Chang J, Yao J, Huang Q (2016) Integrated assessment for hydrometeorological drought based on Markov chain model. Nat Hazard 84(2):1-24

80. Yang J, Chang J, Wang Y, Li Y, Hu H, Chen Y, Huang Q, Yao J (2018) Comprehensive drought characteristics analysis based on a nonlinear multivariate drought index. J Hydrol 557:651-667

81. Yu M, Li Q, Hayes MJ, Svoboda MD, Heim RR (2014) Are droughts becoming more frequent or severe in China based on the standardized precipitation evapotranspiration index: 1951-2010? Int J Climatol 34:545-558

82. Yusof $F$, Hui-Mean $F(2012)$ Use of statistical distribution for drought analysis. Appl Math Sci 6(21):1031-1051

83. Zhang Q, Xiao M, Singh VP, Chen X (2013) Copula based risk evaluation of hydrological droughts in the East River basin, China. Stoch Environ Res Risk A 27(6):1397-1406

84. Zhang D, Yan D, Lu F, Wang Y, Feng J (2015) Copula-based risk assessment of drought in Yunnan province, China. Nat Hazards 75:2199-2220

85. Zhu Y, Chang J, Huang S, Huang Q (2015) Characteristics of integrated droughts based on a nonparametric standardized drought index in the Yellow River Basin, China. Hydrol Res 47:454-467

86. Zou L, Xia J, She D (2017) Drought characteristic analysis based on an improved PDSI in the Wei River Basin of China. Water 9:178. https://doi.org/10.3390/w9030178

Publisher's Note Springer Nature remains neutral with regard to jurisdictional claims in published maps and institutional affiliations. 